\title{
Chemical and microstructural characterization of (Y or Zr)-doped CrAIN
}

\section{coatings}

T.C. Rojas ${ }^{\mathrm{a}}$, S. El Mrabet ${ }^{\mathrm{a}}$, S. Domínguez-Meister ${ }^{\mathrm{a}}$, M. Brizuela ${ }^{\mathrm{b}}$, A. García-Luis $^{\mathrm{b}}$, J.C. Sánchez-López ${ }^{\mathrm{a}}$

${ }^{a}$ Instituto de Ciencia de Materiales de Sevilla (CSIC-Univ. Sevilla), Avda. Américo Vespucio 49, 41092-Sevilla, Spain

${ }^{\mathrm{b}}$ TECNALIA, Mikeletegui Pasealekua, 2 20009 Donostia-San Sebastián, Spain

\begin{abstract}
Magnetron sputtered chromium aluminium nitride films are excellent candidates for advanced machining and protection for high temperature applications. In this work CrAlNbased coatings including $\mathrm{Y}$ or $\mathrm{Zr}$ as dopants $(\approx 2$ at. $\%)$ are deposited by d.c. reactive magnetron sputtering on silicon substrates using metallic targets and $\operatorname{Ar} / \mathrm{N}_{2}$ mixtures. The hardness properties are found in the range of 22-33 GPa with $\mathrm{H} / \mathrm{E}$ ratios close to 0.1 . The influence of the dopant element in terms of oxidation resistance after heating in air at $1000^{\circ} \mathrm{C}$ is studied by means of X-ray diffraction (XRD), cross-sectional scanning electron microscopy (X-SEM) and energy dispersive X-ray analysis (EDAX). The microstructure and chemical bonding are investigated using a transmission electron microscope (TEM) and electron energy-loss spectroscopy (EELS) respectively. The improvement in oxidation resistance as compared to pure $\mathrm{CrN}$ coating is manifested in the formation of a Al-rich outer layer that protects the underneath coating from oxygen diffusion. The best performance obtained with the CrAlYN film is investigated by in situ annealing of this sample inside the TEM in order to gain knowledge about the structural and chemical transformations induced during heating.
\end{abstract}




\section{Introduction}

$\mathrm{Cr}_{1-\mathrm{x}} \mathrm{Al}_{\mathrm{x}} \mathrm{N}$ films deposited by physical vapour deposition have proven to be effective protective coatings for machining applications and are promising candidates for various other high temperature applications [1-7]. The incorporation of $\mathrm{Al}$ to $\mathrm{CrN}$ results in higher hardness, thermal and chemical stability, allowing increased efficiency of cutting and forming tools $[8,9]$. The concentration of $\mathrm{Al}$ inside the coating is tried to be controlled below $70 \mathrm{~mol}$ $\%$ in order to form the metastable solid solution of $\mathrm{Al}$ inside the fcc $\mathrm{CrN}$ lattice $[10,11]$. The formation of hexagonal AIN structure usually exhibits lower hardness and elastic moduli, which results in lower wear resistance. When exposed to air at elevated temperatures, $\mathrm{Cr}_{1-}$ ${ }_{x} \mathrm{Al}_{\mathrm{x}} \mathrm{N}$ films form dense and adherent mixed aluminium and chromium oxide scales $[1,8,12]$, which eventually suppress the oxygen diffusion into the bulk, providing excellent oxidation resistance up to temperatures as high as $900^{\circ} \mathrm{C}$ [13-15]. Current investigations seek to improve the thermal and oxidation resistance above this limit temperature by incorporation of large (substitutional) atoms, as they effectively retard diffusion related processes (recovery, decomposition and recrystallization). Ytrium has been proposed to be effective for this purpose by segregation to the oxide scale grain boundaries, blocking fast diffusion paths and increasing the onset for decomposition to $1100^{\circ} \mathrm{C}$ [16-20]. Moreover, the addition of a reactive element was suggested to reduce the accumulation of voids at the substrate/scale interface [21] or to improve the mechanical properties of the scale by modifying the oxide scale structure [22]. In previous works [4,5] we have shown the increment of the oxidation resistance of a CrAlN coating above $800^{\circ} \mathrm{C}$. In view of the beneficial effects of $\mathrm{Y}$, the present work was undertaken to investigate the prospect of adding $\mathrm{Y}$ to a similar CrAlN coating to improve the oxidation behaviour. Besides, in an attempt to establish some fundamental understanding on the oxidation mechanism, another large substitutional atom like $\mathrm{Zr}$ is incorporated instead of $\mathrm{Y}$ at similar concentration to check the influence of the type of dopant. 


\section{Experimental details}

CrAl(Y,Zr)N coatings were prepared on Si (100) substrates by de magnetron sputtering using $\mathrm{Ar} / \mathrm{N}_{2}$ mixtures in a commercial equipment (CemeCon $\left.{ }^{\circledR} \mathrm{CC} 800 / 8\right)$ provided with four rectangular targets $(200 \mathrm{~mm} \times 88 \mathrm{~mm} \times 5 \mathrm{~mm})$ : two of chromium $(99.9 \%$ purity), one of aluminum (99.5\% purity) and the last one either of yttrium or zirconium (99.5\% purity). The base pressure of the vacuum chamber was $\sim 1 \times 10^{-4} \mathrm{~Pa}$ and the working pressure set at $1 \mathrm{~Pa}$, with at $\mathrm{Ar} / \mathrm{N}_{2}$ ratio of 1.5 . The sputtering conditions were set to $3000 \mathrm{~W}$ for the chromium and aluminium and $1500 \mathrm{~W}$ for $\mathrm{Y}$ or $\mathrm{Zr}$ targets. The sample holder was negatively biased in the range of $110-120 \mathrm{~V}$ and the temperature ranged from 200 to $400{ }^{\circ} \mathrm{C}$ due to plasma heating effect.

Chemical composition of the samples was obtained by electron probe microanalysis (EPMA). The EPMA equipment was a JEOL JXA-8200 SuperProbe instrument equipped with four wavelengths detectors (WDS) and one energy-dispersive X-ray (EDX). The X-ray diffraction patterns were obtained in a X'Pert Pro PANALYTICAL diffractometer in the conventional $\theta-2 \theta$ Bragg-Brentano configuration using $\mathrm{Cu} \mathrm{K}_{\alpha}$ radiation. The morphology and thickness of the coatings was investigated by scanning electron microscopy (SEM) performed in a high resolution FEG microscope, HITACHI-4800. Samples grown on silicon substrates were cleaved for SEM cross-section examination. Transmission electron microscopy (TEM) and electron energy-loss spectroscopy (EELS) were carried out in a Philips CM20 microscope operating at $200 \mathrm{kV}$ equipped with a PEELS spectrometer (Gatan). For the TEM observation, cross sectional specimens were prepared in the conventional manner by mechanical polishing followed by $\mathrm{Ar}^{+}$ion milling to electron transparency. The EELS data were acquired in the diffraction mode with a camera length of $470 \mathrm{~mm}$, a 2-mm spectrometer entrance aperture and a collection angle of $1.45 \mathrm{mrad}$. These conditions yielded an energy resolution at the zero loss peak of $1.2 \mathrm{eV}$. After the subtraction of the background and the deconvolution for plural scattering, the spectra were normalized to the jump. All of these treatments were performed 
within the EL/P program (Gatan). The mechanical properties were measured with a Fischerscope H100 dynamic microprobe instrument using a conventional Vickers indenter at loads up to $10 \mathrm{mN}$. The maximum load was selected in such a way that the maximum indentation depth did not exceed $10-15 \%$ of the coating thickness in order to avoid the influence of the substrate.

\section{Results and discussion}

\subsection{Chemical and microstructural characterization}

Table 1 summarizes the chemical composition obtained by EPMA and hardness and Young's modulus values for the coatings. The hardness properties are found in the range of 22-33 GPa with $\mathrm{H} / \mathrm{E}$ ratios close to 0.1 . The microcrystalline structure of the four samples under study is shown in the Bragg-Brentano XRD scans of Fig. 1. It can be seen that the CrNbased coatings exhibit the main peaks corresponding to $\mathrm{CrN}$ calsbergite (JCPDS 01-0762494) although with different preferred orientation and degree of crystallinity depending on the sample. The incorporation of metals ( $\mathrm{Al}$ and $\mathrm{Y}$ or $\mathrm{Zr}$ ) into the $\mathrm{CrN}$ lattice results in broader XRD peaks indicating smaller crystalline domains and change of texture. Thus, the CrAlZrN coating is less textured, more similar to $\mathrm{CrN}$, with $<111>$ preferred orientation. In the case of CrAlN and CrAlYN films, the preferred orientations are observed to shift to $<220>$ and $<200>$ respectively.

Representative cross-section SEM micrographs of the CrN, CrAlN, CrAlZrN and CrAlYN films are shown in Fig. 2. The film thickness values typically vary in the $2-3 \mu \mathrm{m}$ range for the CrAlN-based coatings and $5.8 \mu \mathrm{m}$ for $\mathrm{CrN}$. The exact values are included in the Table 1 . A typical columnar structure is observed although certain differences in column width and porosity can be noticed. A more detailed analysis by X-TEM allowed to determine the lateral size of the columns being estimated in $80 \mathrm{~nm}$ for the CrAlN sample, $60-70 \mathrm{~nm}$ for CrAlZrN and 100-110 nm for the CrAlYN sample. These width values correlate with the measured 
hardness in the sense that smaller columnar sizes generate more compact structures and accordingly higher hardness properties. Fig 3 shows a conventional bright field X-TEM image corresponding to the sample CrAlYN as representative example of the developed film microstructure. From this picture it is clearly noticed that besides of the typical columnar microstructure along the growing direction a periodic layered structure, parallel to the substrate, is observed. This layered architecture is formed by individual layers of different thickness (20-30 $\mathrm{nm}$ the darker layer and 4-8 $\mathrm{nm}$ the brighter one). This periodic layered structure appears in the three CrAlN-based samples and could be related to the configuration of the substrates in respect to the magnetron sources. Similar multilayer structures have been observed in films prepared by magnetron sputtering due to the rotation of the samples alongside the different targets $[23,24]$. The selected area electron diffraction (SAED) pattern obtained for this coating is including as inset in Fig. 3. The presence of diffraction rings is indicative of the polycrystalline nature of the sample. The diffraction rings can be assigned to the planes (111), (002) and (220) corresponding to the cubic phase of $\mathrm{Cr}(\mathrm{Al}) \mathrm{N}$ phase. Moreover, it is observed a certain preferential orientation of the crystallites of the (200) and (111) planes along the growing direction.

In Fig. 4 a high-resolution transmission electron micrograph obtained from a cross-section image of the CrAlYN sample is presented. The measured d-spacing of the lattice fringes is 2.4 $\AA$ that can be assigned to the (111) plane of cubic $\mathrm{Cr}(\mathrm{Al}) \mathrm{N}$ phase. The dashed and dotted lines are plotted as eye-guide to indicate the separation between the columnar and the multilayer structure respectively. It is worth of mentioning the structural crystalline coherency existing between the two layers with different contrast abovementioned. The EELS analysis performed in the TEM preparations of the coatings is a powerful tool to determine the chemical bonding state in nanostructured and multiphase systems [25]. The O-K, N-K and $\mathrm{Cr}_{-}-\mathrm{L}_{2,3}$ spectra have been measured for all the CrAlN-based samples and compared to $\mathrm{CrN}$ [26], $\mathrm{Cr}_{2} \mathrm{~N}$ and c-AlN [27] references compounds used as fingerprints. The hcp-AlN spectrum is not considered as 
the change of crystal structure of $\mathrm{Cr}_{1-\mathrm{x}} \mathrm{Al}_{\mathrm{x}} \mathrm{N}$ from cubic to hexagonal appears at $\mathrm{x}$ values of 0.6-0.7 $[10,11]$, much higher than those shown by the coatings under study. The fine structure of the N-K edge is known to be sensitive to the local atomic environment and consequently it can be used for identification of the chromium nitrides [26]. No O-K edge could be detected in none of the samples in agreement with the low values of oxygen measured by EPMA $(<1$ at. \%). Fig. 5 depicts the normalized N-K and $\mathrm{Cr}-\mathrm{L}_{2,3}$ edges spectra for the all the samples and those corresponding to the reference compounds. Some different features can be highlighted by comparison of the spectra. The N-K edge of chromium nitrides show two main features at about 400 and $410 \mathrm{eV}$ although they differ in intensity. Thus, the second characteristic resonance peak is less pronounced for the $\mathrm{Cr}_{2} \mathrm{~N}$ in comparison to the $\mathrm{CrN}$. The edge onset for the cubic form of AlN appears at higher energies, displaying the most intense energy-loss peak around $407 \mathrm{eV}$. The ELNES structure of the N-K edge for the three $\mathrm{Cr}(\mathrm{Al}) \mathrm{N}$-based coatings is similar to the $\mathrm{CrN}$ reference with the particularities of a diminution of the intensity of the first peak and the detection of a small shoulder at $\sim 407 \mathrm{eV}$. These differences can be attributed to the $\mathrm{Al}$ incorporation in the $\mathrm{CrN}$ phase and/or the formation of $\mathrm{AlN}$ phases in the coatings. Nevertheless, according to the low Al content and previous published works the observed changes can be rather associated to the incorporation of $\mathrm{Al}$ inside the cubic $\mathrm{CrN}$ lattice forming metastable cubic $\mathrm{Cr}_{1-\mathrm{x}} \mathrm{Al}_{\mathrm{x}} \mathrm{N}$ structures $[10,11,13]$. The $\mathrm{Cr}-\mathrm{L}_{2,3}$ edge spectra, represented in Fig 5 (right), only differ in the relative intensity of the $\mathrm{L}_{2}$ and $\mathrm{L}_{3}$ resonances. The values for the $L_{3} / L_{2}$ ratios $(\Delta y)$ have been measured and the obtained values are included for their comparison. The average values are found around 1.25 closer to a $\mathrm{CrN}$, confirming the identification of the $\mathrm{CrN}$ as the chromium nitride phase formed in the CrAlN-based coatings. A further detailed investigation is currently undergoing on this layered microstructure in a FEG STEM microscope with EELS spectroscopy and HAADF detector with bigger lateral resolution to complete the film characterization. 


\subsection{Thermal and oxidation resistance}

In order to study the oxidation resistance the samples have been annealed in air at $1000^{\circ} \mathrm{C}$ during 2h. SEM/EDX cross-section images of CrN, CrAlN, CrAlZrN and CrAlYN films after this thermal treatment are shown in Fig. 6. In the CrN sample, the oxidation has destroyed the original columnar microstructure leading to a polycrystalline morphology where the crystals on the surface grew larger. On the contrary, the remaining samples still maintain the same columnar microstructure as-deposited and a top layer of different contrast whose thickness depends on the sample $(300 \mathrm{~nm}, 750 \mathrm{~nm}$ and $175 \mathrm{~nm}$ for pure CrAlN and Zr- and Ycontaining samples respectively). The chemical composition of the outermost and inner layers was analysed by EDX to investigate the influence of the dopant $\mathrm{Y}$ or $\mathrm{Zr}$ in the film oxidation. It must be mentioned that similar analysis carried out in the $\mathrm{CrN}$ film (not shown) identified only $\mathrm{Cr}$ and $\mathrm{O}$ signals, indicating fully oxidation. Fig. 7 shows the EDX spectra performed in the top layers and inner regions together with an elemental composition profile along the entire thickness of the coatings. As expected the top layer is formed by chromium and aluminium oxides formed by outward and inward diffusion of these metals and oxygen respectively. However, it is clearly inferred that oxygen progressed further in the CrAlZrN coating, forming a larger oxides scale. Comparing the EDX spectra shown in Figs. 7a and 7b, the nitrogen signal is comparatively much lower in the CrAlZrN sample indicating that oxidation process progresses to a further extent. The intensity ratio $\mathrm{O} / \mathrm{N}$ measured from the EDX spectra was found to be $0.9(\mathrm{CrAlZrN})$ and $0.4(\mathrm{CrAlYN})$ in agreement with previous results. Attending to the $\mathrm{Zr}$ and $\mathrm{Y}$ signals it is observed a $\mathrm{Zr}$ depletion in the oxide layer while the $\mathrm{Y}$ content remains almost constant in the inner and outer part. The good oxidation resistance was also confirmed by examining the coatings by XRD after heating up to $1000^{\circ} \mathrm{C}$. Fig. 8 depicts the XRD patterns where it can be seen the (111), (200) and (220) reflections of $\mathrm{Cr}(\mathrm{Al}) \mathrm{N}$ phase as predominant component besides incipient peaks from $\mathrm{Cr}_{2} \mathrm{O}_{3}$ phase. No 
significant differences in intensity are observed depending on the type of dopant ( $\mathrm{Zr}$ or $\mathrm{Y}$ ) although it can be noticed that the $\mathrm{Cr}_{2} \mathrm{O}_{3}$ crystallites are more randomly distributed in the case of CrAlZrN than in the CrAlYN film where the $<120>$ at $41.6^{\circ}$ is the preferential orientation. Aluminium oxides are not detected indicating that this element must be present forming mixtures with chromium oxides or in amorphous state. This fact might be an influence of ytrium element on the growth mechanism of the oxide scale that yielded an improved resistance against oxidation. In summary, these results demonstrate a better protection against oxidation of CrAlYN coating composition up to temperatures of $1000^{\circ} \mathrm{C}$. Ytrium atoms appear to diffuse out concomitantly with $\mathrm{Cr}$ and $\mathrm{Al}$ forming a more efficient protective oxide layer whilst $\mathrm{Zr}$ atoms however seems to concentrate in the unaltered film structure.

With the aim of obtaining complementary information on the chemical and microstructural changes occurring during heating an in situ annealing of the CrAlYN sample was carried out inside the TEM microscope. In Fig. 9a the EELS spectra (N-K and O-K edges) measured at different temperatures are shown. The $\mathrm{O}-\mathrm{K}$ edge begins to appear at $1100^{\circ} \mathrm{C}$, below this temperature no oxygen signal is clearly detected. The N-K edge fine structure becomes more defined with the increase of the temperature, especially above $750^{\circ} \mathrm{C}$, indicative of a better crystallised CrAlN phase. The most significant happened at $1100^{\circ} \mathrm{C}$ when oxygen entered into the film structure. This change is related to the decomposition of the nitride by $\mathrm{N}_{2}$-removal and oxygen incorporation as described in previous publications [1,14,17]. A representative TEM image taken at $\sim 1000^{\circ} \mathrm{C}$, just before the degradation start-up, (cf. Fig. $9 \mathrm{~b}$ ) shows that inside the coating the microstructure remains almost unaltered. The layered structure is maintained but with higher degree of the crystallinity inside the CrAlN phase as demonstrated by XRD.

\section{Conclusions}


The thermal and oxidation resistance of CrAlN-based coatings doped with $\mathrm{Zr}$ or $\mathrm{Y}(\approx 2$ at.\%) prepared by magnetron sputtering have been studied comparatively. The prepared coatings are mainly constituted by cubic $\mathrm{Cr}(\mathrm{Al}) \mathrm{N}$ phase and show a dense columnar microstructure that resisted the oxidation in air up to $1000^{\circ} \mathrm{C}$ although certain differences in oxidation rate are noticed. Thus, the beneficial effect of aluminium as protective agent of $\mathrm{CrN}$ phases against oxygen reactivity is reinforced in the case of yttrium, reducing the oxidation rate and modifying the oxide growth mechanism. The addition of this element promotes the formation of a dense mixed ( $\mathrm{Cr}, \mathrm{Al}$ )-oxide top layer that avoids inward diffusion of oxygen. Zirconium atoms did not diffuse together with $\mathrm{Cr}$ and $\mathrm{Al}$ and the oxidation progresses to a greater extent. The microstructural and chemical transformations induced during thermal treatment were followed in situ by TEM/EELS analysis confirming a high stability up to $1000^{\circ} \mathrm{C}$ where the coating began to decompose and oxidize.

\section{Acknowledgments}

The authors are grateful to the Spanish Ministry of Science and Innovation (projects No. MAT2007-66881-C02-01, MAT2010-21597-C02-01 and Consolider FUNCOAT CSD200800023), Junta de Andalucía (TEP217) and I3P programme of CSIC for financial support. 


\section{References}

1. O. Banakh, P. E. Schmid, R. Sanjinés, F. Lévy, Surf. Coat. Technol. 163-164 (2003) 57.

2. M. Kawate, A.K. Hashimoto, T. Suzuki, Surf. Coat. Technol. 165 (2003)163.

3. A.E. Reiter, V.H. Derflinger, B. Hanselmann, T. Bachmann, B. Sartory, Surf. Coat. Technol. 7 (2005) 2114.

4. J.C. Sánchez-López, D. Martínez-Martínez, C. López-Cartes, A. Fernández, M. Brizuela, A. García-Luis, J.I. Oñate, J. Vac. Sci. Technol. A 23, 681-686 (2005).

5. M. Brizuela, A. García, I. Braceras, J.I. Oñate, J.C. Sánchez-López, D. MartínezMartínez, C. López-Cartes, A. Fernández, Surf. Coat. Technol. 200, 192-197 (2005).

6. H.C. Barshilia, N. Selvakumar, B. Deepthi, K.S. Rajam, Surf. Coat. Technol. 201 (2006) 2193.

7. J. Lin, B. Mishra, J.J. Moore, W.D. Sproul, Surf. Coat. Technol. 201 (2006) 4329.

8. J.L. Endrino, G.S. Fox-Rabinovich, A. Reiter, S.V. Veldhuis, R. Escobar Galindo, J.M. Albella, J.F. Marco, Surf. Coat. Technol. 201 (2007) 4505.

9. L. Wang, X. Nie, J. Housden, E. Spain, J.C. Jiang, E.I. Meletis, A. Leyland, A. Matthews, Surf. Coat. Technol. 203 (2008) 816.

10. H. Hasegawa, M. Kawate, T. Suzuki, Surf. Coat. Technol. 200 (2005) 2409.

11. P.H. Mayrhofer, D. Music, Th. Reeswimkel, H.-G. Fuss, J.M. Schneider, Acta Mater. 56 (2008) 2469.

12. R. Escobar Galindo, J.L. Endrino, R. Martínez, J.M. Albella, Spectrochimica Acta Part B 65 (2010) 950-958.

13. M. Kawate, A. K. Hashimoto, T. Suzuki, Surf. Coat. Technol. 165 (2003)163.

14. H. Willmann, P.H. Mayrhofer, P.O.A. Persson, A. E. Reiter, L. Hultman, C. Mitterer, Scripta Mater. 54 (2006) 1847.

15. H.C. Barshilia, B. Deepthi, K.S. Rajam, K.P. Bhatti, S. Chaudhary, J. Vac. Sci. Technol. A 27 (2009) 29.

16. F. Rovere, P. H. Mayrhofer, A. Reinholdt, J. Mayer, J.M. Schneider, Surf. Coat. Technol. 202 (2008) 5870.

17. F. Rovere, P. H. Mayrhofer, J. Vac. Sci. Technol. A 26 (2008) 29.

18. K.-D. Bouzakis, N. Michailidis, S. Gerardis, G. Katirtzoglou, E. Lili, M. Pappa, M. Brizuela, A. Garcia-Luis, R. Cremer, Surf. Coat. Technol. 203 (2008) 781.

19. F. Rovere, D. Music, J. M. Schneider, P. H. Mayrhofer, Acta Mater. 58 (2010) 2708. 
20. R. Braun, F. Rovere, P.H. Mayrhofer, C. Leyens, Intermetallics 18 (2010) 479.

21. D.P. Whittle, J. Stringer, Philos. Trans. R. Soc. London Ser. A-Math. Phys. Eng. Sci. 295 (1980) 309.

22. Y. Saito, T. Maruyama, T. Amano, Mater. Sci. Eng. 87 (1987) 275.

23. M. Panjan, T. Peterman, M. Cekada, P. Panjan, Surf. Coat. Technol. 204 (2009) 850.

24. M. Panjan, S. Sturn, P. Panjan, M. Cekada, Surf. Coat. Technol. 203 (2008) 554.

25. D. Martínez-Martínez, C. López-Cartes, A. Justo, A. Fernández, J. C. Sánchez-López, A. García-Luis, M. Brizuela, J. I. Oñate. J. Vac. Sci. Technol. A 23, 1732-1736 (2005).

26. C. Mitterbauer, C. Hébert, G. Kothleitner, F. Hofer, P. Schattschneider, H.W. Zandbergen, Solid State Comm. 130 (2004) 209.

27. M. Mackenzie, GC. Weatherly, D.W. McComb, A.J. Craven, Scripta Materialia 53 (2005) 983-987.

28. H. Hasegawa, K. Ohashi, S. Tsukamoto, T. Sato, T. Suzuki, Surf. Coat. Technol. 202 (2007) 786. 


\section{Figure captions}

1. XRD diffractograms of the $\mathrm{CrAl}(\mathrm{Y}, \mathrm{Zr}) \mathrm{N}$ coatings under study. A CrN diffraction pattern is included for comparison purposes.

2. SEM cross-sectional views of the CrN, CrAlN, CrAlZrN and CrAlYN coatings.

3. X-TEM image obtained from the CrAlYN coating. The SAED pattern is included as inset.

4. HRTEM image obtained from a cross-section preparation of the CrAIYN coating.

5. N-K and $\mathrm{Cr}-\mathrm{L}_{2,3}$ edges of the EELS spectra for all the CrAlN-based samples and those corresponding to the reference compounds $\left(\mathrm{CrN}, \mathrm{Cr}_{2} \mathrm{~N}\right.$ and c-AlN).

6. X-SEM images taken after oxidation in air at $1000^{\circ} \mathrm{C}$ of the $\mathrm{CrN}, \mathrm{CrAlN}, \mathrm{CrAlZrN}$ and CrAlYN coatings.

7. EDX analysis carried out in the cross section preparations of the CrAlZrN and CrAlYN samples after heating at $1000^{\circ} \mathrm{C}$. Spectra obtained from the topmost layer and inner part of the CrAlZrN (left) and CrAlYN (right) coatings. Elemental chemical composition profile obtained across the CrAlZrN (left) and CrAlYN (right) coatings.

8. XRD diffractograms of the CrAlZrN and CrAlYN coatings after oxidation in air at $1000^{\circ}$. ( symbols correspond to CrN (JCPDS card\# 01-076-2494) and $\star$ symbols correspond to $\mathrm{Cr}_{2} \mathrm{O}_{3}$ peaks (JCPDS card\# 01-076-0147).

9. a) Evolution of the N-K and O-K edge EELS spectra of the CrAlYN sample during annealing in vacuum up to $1000^{\circ} \mathrm{C}$ and b) TEM picture revealing the multilayered structure before total decomposition produced at $1100^{\circ} \mathrm{C}$. 


\title{
Chemical and microstructural characterization of ( $\mathrm{Y}$ or $\mathrm{Zr}$ )-doped $\mathrm{CrAlN}$
}

\section{coatings}

T.C. Rojas ${ }^{\mathrm{a}}$, S. El Mrabet ${ }^{\mathrm{a}}$, S. Domínguez-Meister ${ }^{\mathrm{a}}$, M. Brizuela ${ }^{\mathrm{b}}$, A. García-Luis $^{\mathrm{b}}$, J.C. Sánchez-López ${ }^{\mathrm{a}}$

${ }^{a}$ Instituto de Ciencia de Materiales de Sevilla (CSIC-Univ. Sevilla), Avda. Américo Vespucio 49, 41092-Sevilla, Spain

${ }^{\mathrm{b}}$ TECNALIA, Mikeletegui Pasealekua, 2 20009 Donostia-San Sebastián, Spain

\begin{abstract}
Magnetron sputtered chromium aluminium nitride films are excellent candidates for advanced machining and protection for high temperature applications. In this work CrAlNbased coatings including $\mathrm{Y}$ or $\mathrm{Zr}$ as dopants $(\approx 2$ at. $\%)$ are deposited by d.c. reactive magnetron sputtering on silicon substrates using metallic targets and $\operatorname{Ar} / \mathrm{N}_{2}$ mixtures. The hardness properties are found in the range of $22-33 \mathrm{GPa}$ with $\mathrm{H} / \mathrm{E}$ ratios close to 0.1 . The influence of the dopant element in terms of oxidation resistance after heating in air at $1000^{\circ} \mathrm{C}$ is studied by means of X-ray diffraction (XRD), cross-sectional scanning electron microscopy (X-SEM) and energy dispersive X-ray analysis (EDAX). The microstructure and chemical bonding are investigated using a transmission electron microscope (TEM) and electron energy-loss spectroscopy (EELS) respectively. The improvement in oxidation resistance as compared to pure $\mathrm{CrN}$ coating is manifested in the formation of a Al-rich outer layer that protects the underneath coating from oxygen diffusion. The best performance obtained with the CrAlYN film is investigated by in situ annealing of this sample inside the TEM in order to gain knowledge about the structural and chemical transformations induced during heating.
\end{abstract}




\section{Introduction}

$\mathrm{Cr}_{1-\mathrm{x}} \mathrm{Al}_{\mathrm{x}} \mathrm{N}$ films deposited by physical vapour deposition have proven to be effective protective coatings for machining applications and are promising candidates for various other high temperature applications [1-7]. The incorporation of $\mathrm{Al}$ to $\mathrm{CrN}$ results in higher hardness, thermal and chemical stability, allowing increased efficiency of cutting and forming tools $[8,9]$. The concentration of $\mathrm{Al}$ inside the coating is tried to be controlled below $70 \mathrm{~mol}$ $\%$ in order to form the metastable solid solution of $\mathrm{Al}$ inside the fcc $\mathrm{CrN}$ lattice $[10,11]$. The formation of hexagonal AIN structure usually exhibits lower hardness and elastic moduli, which results in lower wear resistance. When exposed to air at elevated temperatures, $\mathrm{Cr}_{1-}$ ${ }_{x} \mathrm{Al}_{\mathrm{x}} \mathrm{N}$ films form dense and adherent mixed aluminium and chromium oxide scales $[1,8,12]$, which eventually suppress the oxygen diffusion into the bulk, providing excellent oxidation resistance up to temperatures as high as $900^{\circ} \mathrm{C}$ [13-15]. Current investigations seek to improve the thermal and oxidation resistance above this limit temperature by incorporation of large (substitutional) atoms, as they effectively retard diffusion related processes (recovery, decomposition and recrystallization). Ytrium has been proposed to be effective for this purpose by segregation to the oxide scale grain boundaries, blocking fast diffusion paths and increasing the onset for decomposition to $1100^{\circ} \mathrm{C}$ [16-20]. Moreover, the addition of a reactive element was suggested to reduce the accumulation of voids at the substrate/scale interface [21] or to improve the mechanical properties of the scale by modifying the oxide scale structure [22]. In previous works [4,5] we have shown the increment of the oxidation resistance of a CrAlN coating above $800{ }^{\circ} \mathrm{C}$. In view of the beneficial effects of Y, the present work was undertaken to investigate the prospect of adding $\mathrm{Y}$ to a similar CrAlN coating to improve the oxidation behaviour. Besides, in an attempt to establish some fundamental understanding on the oxidation mechanism, another large substitutional atom like $\mathrm{Zr}$ is incorporated instead of $\mathrm{Y}$ at similar concentration to check the influence of the type of dopant. 


\section{Experimental details}

$\mathrm{CrAl}(\mathrm{Y}, \mathrm{Zr}) \mathrm{N}$ coatings were prepared on Si (100) substrates by dc magnetron sputtering using $\mathrm{Ar} / \mathrm{N}_{2}$ mixtures in a commercial equipment (CemeCon® $\left.{ }^{\circledR} \mathrm{CC} 800 / 8\right)$ provided with four rectangular targets $(200 \mathrm{~mm} \times 88 \mathrm{~mm} \times 5 \mathrm{~mm})$ : two of chromium $(99.9 \%$ purity $)$, one of aluminum (99.5\% purity) and the last one either of yttrium or zirconium (99.5\% purity). The base pressure of the vacuum chamber was $\sim 1 \times 10^{-4} \mathrm{~Pa}$ and the working pressure set at $1 \mathrm{~Pa}$, with at $\mathrm{Ar} / \mathrm{N}_{2}$ ratio of 1.5. The sputtering conditions were set to $3000 \mathrm{~W}$ for the chromium and aluminium and $1500 \mathrm{~W}$ for $\mathrm{Y}$ or $\mathrm{Zr}$ targets. The sample holder was negatively biased in the range of $110-120 \mathrm{~V}$ and the temperature ranged from 200 to $400{ }^{\circ} \mathrm{C}$ due to plasma heating effect.

Chemical composition of the samples was obtained by electron probe microanalysis (EPMA). The EPMA equipment was a JEOL JXA-8200 SuperProbe instrument equipped with four wavelengths detectors (WDS) and one energy-dispersive X-ray (EDX). The X-ray diffraction patterns were obtained in a X'Pert Pro PANALYTICAL diffractometer in the conventional $\theta-2 \theta$ Bragg-Brentano configuration using $\mathrm{Cu} \mathrm{K}_{\alpha}$ radiation. The morphology and thickness of the coatings was investigated by scanning electron microscopy (SEM) performed in a high resolution FEG microscope, HITACHI-4800. Samples grown on silicon substrates were cleaved for SEM cross-section examination. Transmission electron microscopy (TEM) and electron energy-loss spectroscopy (EELS) were carried out in a Philips CM20 microscope operating at $200 \mathrm{kV}$ equipped with a PEELS spectrometer (Gatan). For the TEM observation, cross sectional specimens were prepared in the conventional manner by mechanical polishing followed by $\mathrm{Ar}^{+}$ion milling to electron transparency. The EELS data were acquired in the diffraction mode with a camera length of $470 \mathrm{~mm}$, a 2-mm spectrometer entrance aperture and a collection angle of $1.45 \mathrm{mrad}$. These conditions yielded an energy resolution at the zero loss peak of $1.2 \mathrm{eV}$. After the subtraction of the background and the deconvolution for plural scattering, the spectra were normalized to the jump. All of these treatments were performed 
within the EL/P program (Gatan). The mechanical properties were measured with a Fischerscope H100 dynamic microprobe instrument using a conventional Vickers indenter at loads up to $10 \mathrm{mN}$. The maximum load was selected in such a way that the maximum indentation depth did not exceed $10-15 \%$ of the coating thickness in order to avoid the influence of the substrate.

\section{Results and discussion}

\subsection{Chemical and microstructural characterization}

Table 1 summarizes the chemical composition obtained by EPMA and hardness and Young's modulus values for the coatings. The hardness properties are found in the range of 22-33 GPa with $\mathrm{H} / \mathrm{E}$ ratios close to 0.1 . The microcrystalline structure of the four samples under study is shown in the Bragg-Brentano XRD scans of Fig. 1. It can be seen that the CrNbased coatings exhibit the main peaks corresponding to CrN calsbergite (JCPDS 01-0762494) although with different preferred orientation and degree of crystallinity depending on the sample. The incorporation of metals ( $\mathrm{Al}$ and $\mathrm{Y}$ or $\mathrm{Zr}$ ) into the $\mathrm{CrN}$ lattice results in broader XRD peaks indicating smaller crystalline domains and change of texture. Thus, the $\mathrm{CrAlZrN}$ coating is less textured, more similar to $\mathrm{CrN}$, with $\langle 111>$ preferred orientation. In the case of CrAlN and CrAlYN films, the preferred orientations are observed to shift to $<220>$ and $<200>$ respectively.

Representative cross-section SEM micrographs of the CrN, CrAlN, CrAlZrN and CrAlYN films are shown in Fig. 2. The film thickness values typically vary in the $2-3 \mu \mathrm{m}$ range for the CrAlN-based coatings and $5.8 \mu \mathrm{m}$ for $\mathrm{CrN}$. The exact values are included in the Table $1 . \mathrm{A}$ typical columnar structure is observed although certain differences in column width and porosity can be noticed. A more detailed analysis by X-TEM allowed to determine the lateral size of the columns being estimated in $80 \mathrm{~nm}$ for the CrAlN sample, $60-70 \mathrm{~nm}$ for CrAlZrN and 100-110 nm for the CrAlYN sample. These width values correlate with the measured 
hardness in the sense that smaller columnar sizes generate more compact structures and accordingly higher hardness properties. Fig 3 shows a conventional bright field X-TEM image corresponding to the sample CrAlYN as representative example of the developed film microstructure. From this picture it is clearly noticed that besides of the typical columnar microstructure along the growing direction a periodic layered structure, parallel to the substrate, is observed. This layered architecture is formed by individual layers of different thickness (20-30 $\mathrm{nm}$ the darker layer and 4-8 $\mathrm{nm}$ the brighter one). This periodic layered structure appears in the three CrAlN-based samples and could be related to the configuration of the substrates in respect to the magnetron sources. Similar multilayer structures have been observed in films prepared by magnetron sputtering due to the rotation of the samples alongside the different targets [23,24]. The selected area electron diffraction (SAED) pattern obtained for this coating is including as inset in Fig. 3. The presence of diffraction rings is indicative of the polycrystalline nature of the sample. The diffraction rings can be assigned to the planes (111), (002) and (220) corresponding to the cubic phase of $\mathrm{Cr}(\mathrm{Al}) \mathrm{N}$ phase. Moreover, it is observed a certain preferential orientation of the crystallites of the (200) and (111) planes along the growing direction.

In Fig. 4 a high-resolution transmission electron micrograph obtained from a cross-section image of the CrAlYN sample is presented. The measured d-spacing of the lattice fringes is 2.4 $\AA$ that can be assigned to the (111) plane of cubic $\mathrm{Cr}(\mathrm{Al}) \mathrm{N}$ phase. The dashed and dotted lines are plotted as eye-guide to indicate the separation between the columnar and the multilayer structure respectively. It is worth of mentioning the structural crystalline coherency existing between the two layers with different contrast abovementioned. The EELS analysis performed in the TEM preparations of the coatings is a powerful tool to determine the chemical bonding state in nanostructured and multiphase systems [25]. The O-K, N-K and $\mathrm{Cr}_{-} \mathrm{L}_{2,3}$ spectra have been measured for all the CrAlN-based samples and compared to $\mathrm{CrN}$ [26], $\mathrm{Cr}_{2} \mathrm{~N}$ and c-AlN [27] references compounds used as fingerprints. The hcp-AlN spectrum is not considered as 
the change of crystal structure of $\mathrm{Cr}_{1-\mathrm{x}} \mathrm{Al}_{\mathrm{x}} \mathrm{N}$ from cubic to hexagonal appears at $\mathrm{x}$ values of 0.6-0.7 $[10,11]$, much higher than those shown by the coatings under study. The fine structure of the $\mathrm{N}-\mathrm{K}$ edge is known to be sensitive to the local atomic environment and consequently it can be used for identification of the chromium nitrides [26]. No O-K edge could be detected in none of the samples in agreement with the low values of oxygen measured by EPMA $(<1$ at. \%). Fig. 5 depicts the normalized $\mathrm{N}-\mathrm{K}$ and $\mathrm{Cr}-\mathrm{L}_{2,3}$ edges spectra for the all the samples and those corresponding to the reference compounds. Some different features can be highlighted by comparison of the spectra. The N-K edge of chromium nitrides show two main features at about 400 and $410 \mathrm{eV}$ although they differ in intensity. Thus, the second characteristic resonance peak is less pronounced for the $\mathrm{Cr}_{2} \mathrm{~N}$ in comparison to the $\mathrm{CrN}$. The edge onset for the cubic form of AlN appears at higher energies, displaying the most intense energy-loss peak around $407 \mathrm{eV}$. The ELNES structure of the $\mathrm{N}-\mathrm{K}$ edge for the three $\mathrm{Cr}(\mathrm{Al}) \mathrm{N}$-based coatings is similar to the $\mathrm{CrN}$ reference with the particularities of a diminution of the intensity of the first peak and the detection of a small shoulder at $\sim 407 \mathrm{eV}$. These differences can be attributed to the $\mathrm{Al}$ incorporation in the $\mathrm{CrN}$ phase and/or the formation of $\mathrm{AlN}$ phases in the coatings. Nevertheless, according to the low Al content and previous published works the observed changes can be rather associated to the incorporation of $\mathrm{Al}$ inside the cubic $\mathrm{CrN}$ lattice forming metastable cubic $\mathrm{Cr}_{1-\mathrm{x}} \mathrm{Al}_{\mathrm{x}} \mathrm{N}$ structures $[10,11,13]$. The $\mathrm{Cr}-\mathrm{L}_{2,3}$ edge spectra, represented in Fig 5 (right), only differ in the relative intensity of the $\mathrm{L}_{2}$ and $\mathrm{L}_{3}$ resonances. The values for the $\mathrm{L}_{3} / \mathrm{L}_{2}$ ratios $(\Delta \mathrm{y})$ have been measured and the obtained values are included for their comparison. The average values are found around 1.25 closer to a $\mathrm{CrN}$, confirming the identification of the $\mathrm{CrN}$ as the chromium nitride phase formed in the CrAlN-based coatings. A further detailed investigation is currently undergoing on this layered microstructure in a FEG STEM microscope with EELS spectroscopy and HAADF detector with bigger lateral resolution to complete the film characterization. 


\subsection{Thermal and oxidation resistance}

In order to study the oxidation resistance the samples have been annealed in air at $1000^{\circ} \mathrm{C}$ during 2h. SEM/EDX cross-section images of CrN, CrAlN, CrAlZrN and CrAlYN films after this thermal treatment are shown in Fig. 6. In the CrN sample, the oxidation has destroyed the original columnar microstructure leading to a polycrystalline morphology where the crystals on the surface grew larger. On the contrary, the remaining samples still maintain the same columnar microstructure as-deposited and a top layer of different contrast whose thickness depends on the sample $(300 \mathrm{~nm}, 750 \mathrm{~nm}$ and $175 \mathrm{~nm}$ for pure CrAlN and Zr- and Ycontaining samples respectively). The chemical composition of the outermost and inner layers was analysed by EDX to investigate the influence of the dopant $\mathrm{Y}$ or $\mathrm{Zr}$ in the film oxidation. It must be mentioned that similar analysis carried out in the $\mathrm{CrN}$ film (not shown) identified only $\mathrm{Cr}$ and $\mathrm{O}$ signals, indicating fully oxidation. Fig. 7 shows the EDX spectra performed in the top layers and inner regions together with an elemental composition profile along the entire thickness of the coatings. As expected the top layer is formed by chromium and aluminium oxides formed by outward and inward diffusion of these metals and oxygen respectively. However, it is clearly inferred that oxygen progressed further in the $\mathrm{CrAlZrN}$ coating, forming a larger oxides scale. Comparing the EDX spectra shown in Figs. 7a and 7b, the nitrogen signal is comparatively much lower in the $\mathrm{CrAlZrN}$ sample indicating that oxidation process progresses to a further extent. The intensity ratio $\mathrm{O} / \mathrm{N}$ measured from the EDX spectra was found to be $0.9(\mathrm{CrAlZrN})$ and $0.4(\mathrm{CrAlYN})$ in agreement with previous results. Attending to the $\mathrm{Zr}$ and $\mathrm{Y}$ signals it is observed a $\mathrm{Zr}$ depletion in the oxide layer while the $\mathrm{Y}$ content remains almost constant in the inner and outer part. The good oxidation resistance was also confirmed by examining the coatings by XRD after heating up to $1000^{\circ} \mathrm{C}$. Fig. 8 depicts the XRD patterns where it can be seen the (111), (200) and (220) reflections of $\mathrm{Cr}(\mathrm{Al}) \mathrm{N}$ phase as predominant component besides incipient peaks from $\mathrm{Cr}_{2} \mathrm{O}_{3}$ phase. No 
significant differences in intensity are observed depending on the type of dopant ( $\mathrm{Zr}$ or $\mathrm{Y}$ ) although it can be noticed that the $\mathrm{Cr}_{2} \mathrm{O}_{3}$ crystallites are more randomly distributed in the case of CrAlZrN than in the CrAlYN film where the $\langle 120\rangle$ at $41.6^{\circ}$ is the preferential orientation. Aluminium oxides are not detected indicating that this element must be present forming mixtures with chromium oxides or in amorphous state. This fact might be an influence of ytrium element on the growth mechanism of the oxide scale that yielded an improved resistance against oxidation. In summary, these results demonstrate a better protection against oxidation of $\mathrm{CrAlYN}$ coating composition up to temperatures of $1000^{\circ} \mathrm{C}$. Ytrium atoms appear to diffuse out concomitantly with $\mathrm{Cr}$ and $\mathrm{Al}$ forming a more efficient protective oxide layer whilst $\mathrm{Zr}$ atoms however seems to concentrate in the unaltered film structure.

With the aim of obtaining complementary information on the chemical and microstructural changes occurring during heating an in situ annealing of the CrAlYN sample was carried out inside the TEM microscope. In Fig. 9a the EELS spectra (N-K and O-K edges) measured at different temperatures are shown. The $\mathrm{O}-\mathrm{K}$ edge begins to appear at $1100^{\circ} \mathrm{C}$, below this temperature no oxygen signal is clearly detected. The N-K edge fine structure becomes more defined with the increase of the temperature, especially above $750^{\circ} \mathrm{C}$, indicative of a better crystallised CrAlN phase. The most significant happened at $1100^{\circ} \mathrm{C}$ when oxygen entered into the film structure. This change is related to the decomposition of the nitride by $\mathrm{N}_{2}$-removal and oxygen incorporation as described in previous publications $[1,14,17]$. A representative TEM image taken at $\sim 1000^{\circ} \mathrm{C}$, just before the degradation start-up, (cf. Fig. 9b) shows that inside the coating the microstructure remains almost unaltered. The layered structure is maintained but with higher degree of the crystallinity inside the CrAlN phase as demonstrated by XRD.

\section{Conclusions}


The thermal and oxidation resistance of CrAlN-based coatings doped with $\mathrm{Zr}$ or $\mathrm{Y}(\approx 2$ at.\%) prepared by magnetron sputtering have been studied comparatively. The prepared coatings are mainly constituted by cubic $\mathrm{Cr}(\mathrm{Al}) \mathrm{N}$ phase and show a dense columnar microstructure that resisted the oxidation in air up to $1000^{\circ} \mathrm{C}$ although certain differences in oxidation rate are noticed. Thus, the beneficial effect of aluminium as protective agent of $\mathrm{CrN}$ phases against oxygen reactivity is reinforced in the case of yttrium, reducing the oxidation rate and modifying the oxide growth mechanism. The addition of this element promotes the formation of a dense mixed $(\mathrm{Cr}, \mathrm{Al})$-oxide top layer that avoids inward diffusion of oxygen. Zirconium atoms did not diffuse together with $\mathrm{Cr}$ and $\mathrm{Al}$ and the oxidation progresses to a greater extent. The microstructural and chemical transformations induced during thermal treatment were followed in situ by TEM/EELS analysis confirming a high stability up to $1000^{\circ} \mathrm{C}$ where the coating began to decompose and oxidize.

\section{Acknowledgments}

The authors are grateful to the Spanish Ministry of Science and Innovation (projects No. MAT2007-66881-C02-01, MAT2010-21597-C02-01 and Consolider FUNCOAT CSD200800023), Junta de Andalucía (TEP217) and I3P programme of CSIC for financial support. 


\section{References}

1. O. Banakh, P. E. Schmid, R. Sanjinés, F. Lévy, Surf. Coat. Technol. 163-164 (2003) 57.

2. M. Kawate, A.K. Hashimoto, T. Suzuki, Surf. Coat. Technol. 165 (2003)163.

3. A.E. Reiter, V.H. Derflinger, B. Hanselmann, T. Bachmann, B. Sartory, Surf. Coat. Technol. 7 (2005) 2114.

4. J.C. Sánchez-López, D. Martínez-Martínez, C. López-Cartes, A. Fernández, M. Brizuela, A. García-Luis, J.I. Oñate, J. Vac. Sci. Technol. A 23, 681-686 (2005).

5. M. Brizuela, A. García, I. Braceras, J.I. Oñate, J.C. Sánchez-López, D. MartínezMartínez, C. López-Cartes, A. Fernández, Surf. Coat. Technol. 200, 192-197 (2005).

6. H.C. Barshilia, N. Selvakumar, B. Deepthi, K.S. Rajam, Surf. Coat. Technol. 201 (2006) 2193.

7. J. Lin, B. Mishra, J.J. Moore, W.D. Sproul, Surf. Coat. Technol. 201 (2006) 4329.

8. J.L. Endrino, G.S. Fox-Rabinovich, A. Reiter, S.V. Veldhuis, R. Escobar Galindo, J.M. Albella, J.F. Marco, Surf. Coat. Technol. 201 (2007) 4505.

9. L. Wang, X. Nie, J. Housden, E. Spain, J.C. Jiang, E.I. Meletis, A. Leyland, A. Matthews, Surf. Coat. Technol. 203 (2008) 816.

10. H. Hasegawa, M. Kawate, T. Suzuki, Surf. Coat. Technol. 200 (2005) 2409.

11. P.H. Mayrhofer, D. Music, Th. Reeswimkel, H.-G. Fuss, J.M. Schneider, Acta Mater. 56 (2008) 2469.

12. R. Escobar Galindo, J.L. Endrino, R. Martínez, J.M. Albella, Spectrochimica Acta Part B 65 (2010) 950-958.

13. M. Kawate, A. K. Hashimoto, T. Suzuki, Surf. Coat. Technol. 165 (2003)163.

14. H. Willmann, P.H. Mayrhofer, P.O.A. Persson, A. E. Reiter, L. Hultman, C. Mitterer, Scripta Mater. 54 (2006) 1847.

15. H.C. Barshilia, B. Deepthi, K.S. Rajam, K.P. Bhatti, S. Chaudhary, J. Vac. Sci. Technol. A 27 (2009) 29.

16. F. Rovere, P. H. Mayrhofer, A. Reinholdt, J. Mayer, J.M. Schneider, Surf. Coat. Technol. 202 (2008) 5870.

17. F. Rovere, P. H. Mayrhofer, J. Vac. Sci. Technol. A 26 (2008) 29.

18. K.-D. Bouzakis, N. Michailidis, S. Gerardis, G. Katirtzoglou, E. Lili, M. Pappa, M. Brizuela, A. Garcia-Luis, R. Cremer, Surf. Coat. Technol. 203 (2008) 781.

19. F. Rovere, D. Music, J. M. Schneider, P. H. Mayrhofer, Acta Mater. 58 (2010) 2708. 
20. R. Braun, F. Rovere, P.H. Mayrhofer, C. Leyens, Intermetallics 18 (2010) 479.

21. D.P. Whittle, J. Stringer, Philos. Trans. R. Soc. London Ser. A-Math. Phys. Eng. Sci. 295 (1980) 309.

22. Y. Saito, T. Maruyama, T. Amano, Mater. Sci. Eng. 87 (1987) 275.

23. M. Panjan, T. Peterman, M. Cekada, P. Panjan, Surf. Coat. Technol. 204 (2009) 850.

24. M. Panjan, S. Sturn, P. Panjan, M. Cekada, Surf. Coat. Technol. 203 (2008) 554.

25. D. Martínez-Martínez, C. López-Cartes, A. Justo, A. Fernández, J. C. Sánchez-López, A. García-Luis, M. Brizuela, J. I. Oñate. J. Vac. Sci. Technol. A 23, 1732-1736 (2005).

26. C. Mitterbauer, C. Hébert, G. Kothleitner, F. Hofer, P. Schattschneider, H.W. Zandbergen, Solid State Comm. 130 (2004) 209.

27. M. Mackenzie, GC. Weatherly, D.W. McComb, A.J. Craven, Scripta Materialia 53 (2005) 983-987.

28. H. Hasegawa, K. Ohashi, S. Tsukamoto, T. Sato, T. Suzuki, Surf. Coat. Technol. 202 (2007) 786. 


\section{Figure captions}

1. XRD diffractograms of the $\mathrm{CrAl}(\mathrm{Y}, \mathrm{Zr}) \mathrm{N}$ coatings under study. A CrN diffraction pattern is included for comparison purposes.

2. SEM cross-sectional views of the CrN, CrAlN, CrAlZrN and CrAlYN coatings.

3. X-TEM image obtained from the CrAlYN coating. The SAED pattern is included as inset.

4. HRTEM image obtained from a cross-section preparation of the CrAIYN coating.

5. N-K and Cr- $\mathrm{L}_{2,3}$ edges of the EELS spectra for all the CrAlN-based samples and those corresponding to the reference compounds $\left(\mathrm{CrN}, \mathrm{Cr}_{2} \mathrm{~N}\right.$ and c- $\left.\mathrm{AlN}\right)$.

6. X-SEM images taken after oxidation in air at $1000^{\circ} \mathrm{C}$ of the $\mathrm{CrN}, \mathrm{CrAlN}, \mathrm{CrAlZrN}$ and CrAlYN coatings.

7. EDX analysis carried out in the cross section preparations of the CrAlZrN and CrAlYN samples after heating at $1000^{\circ} \mathrm{C}$. Spectra obtained from the topmost layer and inner part of the CrAlZrN (left) and CrAlYN (right) coatings. Elemental chemical composition profile obtained across the CrAlZrN (left) and CrAlYN (right) coatings.

8. XRD diffractograms of the $\mathrm{CrAlZrN}$ and CrAlYN coatings after oxidation in air at $1000^{\circ}$. ( symbols correspond to CrN (JCPDS card\# 01-076-2494) and $\star$ symbols correspond to $\mathrm{Cr}_{2} \mathrm{O}_{3}$ peaks (JCPDS card\# 01-076-0147).

9. a) Evolution of the N-K and O-K edge EELS spectra of the CrAlYN sample during annealing in vacuum up to $1000^{\circ} \mathrm{C}$ and b) TEM picture revealing the multilayered structure before total decomposition produced at $1100^{\circ} \mathrm{C}$. 
Table 1. Chemical composition, thickness and mechanical properties of the $\mathrm{Cr}(\mathrm{Al}) \mathrm{N}$ based coatings.

\begin{tabular}{|c|c|c|c|c|c|c|c|}
\hline & $\mathrm{Cr}$ & $\mathrm{Al}$ & $\mathrm{Y}$ or $\mathrm{Zr}$ & $\mathrm{N}$ & thickness & $\mathrm{H}$ & $\mathrm{E}$ \\
\hline Sample & \multicolumn{4}{|c|}{ at.\% } & $(\mu \mathrm{m})$ & $(\mathrm{GPa})$ & $(\mathrm{GPa})$ \\
\hline $\mathrm{CrN}$ & 45.6 & - & - & 54.4 & 5.8 & 27 & 265 \\
\hline CrAlN & 36.5 & 8.3 & - & 55.2 & 3.3 & 30 & 304 \\
\hline CrAlYN & 38.6 & 5.1 & 1.7 & 54.6 & 2.4 & 22 & 231 \\
\hline CrAlZrN & 38.8 & 4.5 & 2.0 & 54.8 & 2.8 & 33 & 317 \\
\hline
\end{tabular}


Click here to download high resolution image

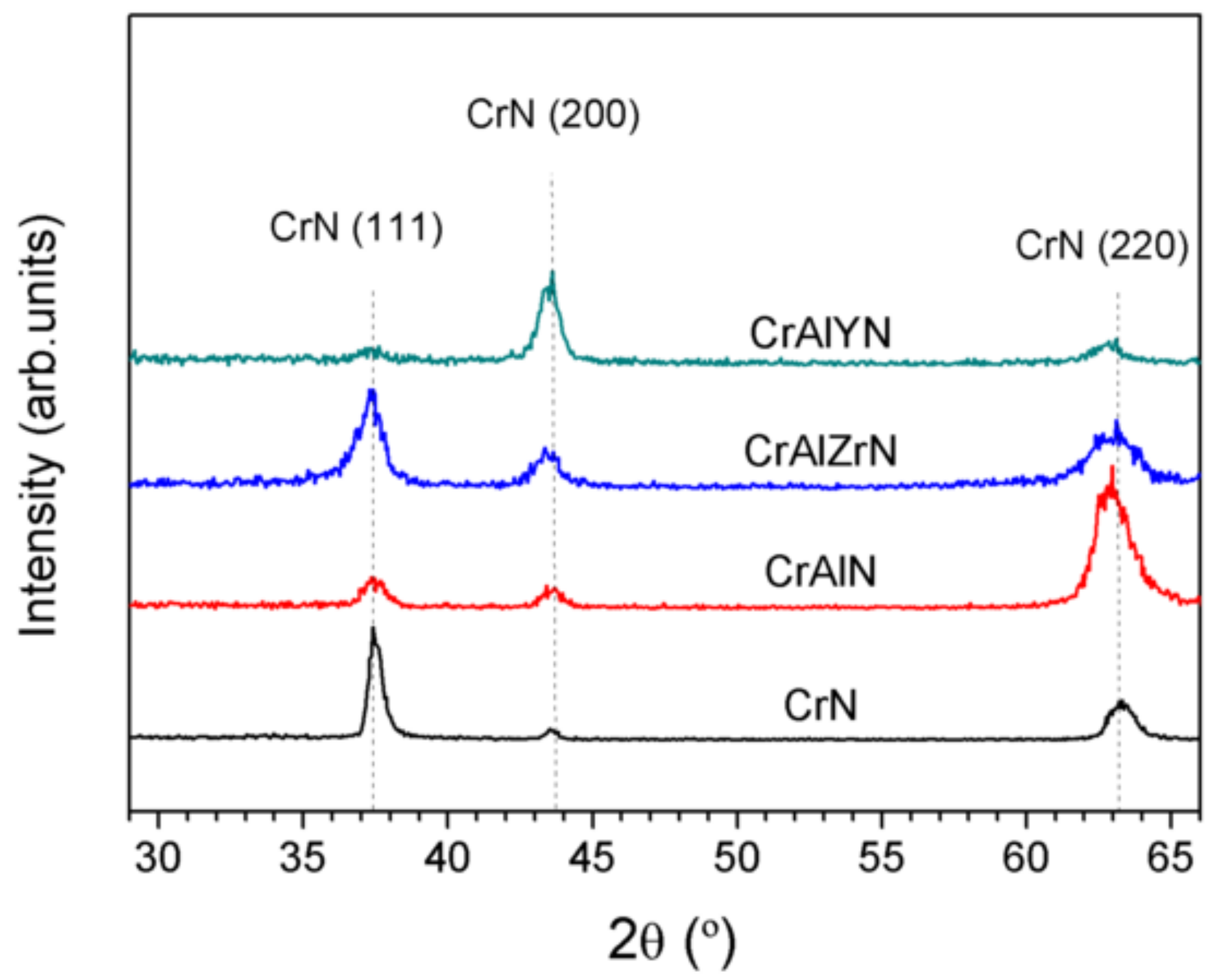




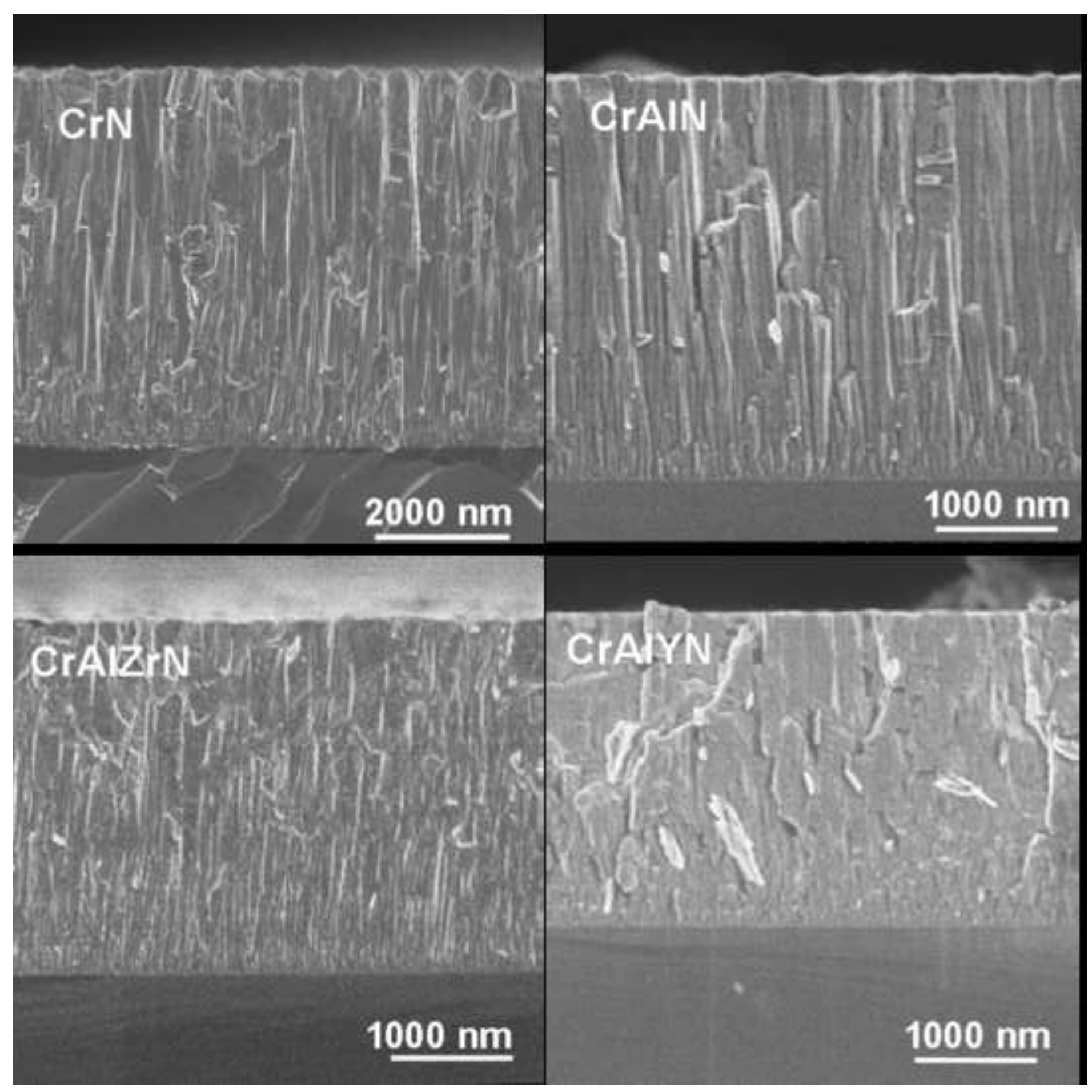


Click here to download high resolution image

\section{$50 \mathrm{~nm}$}

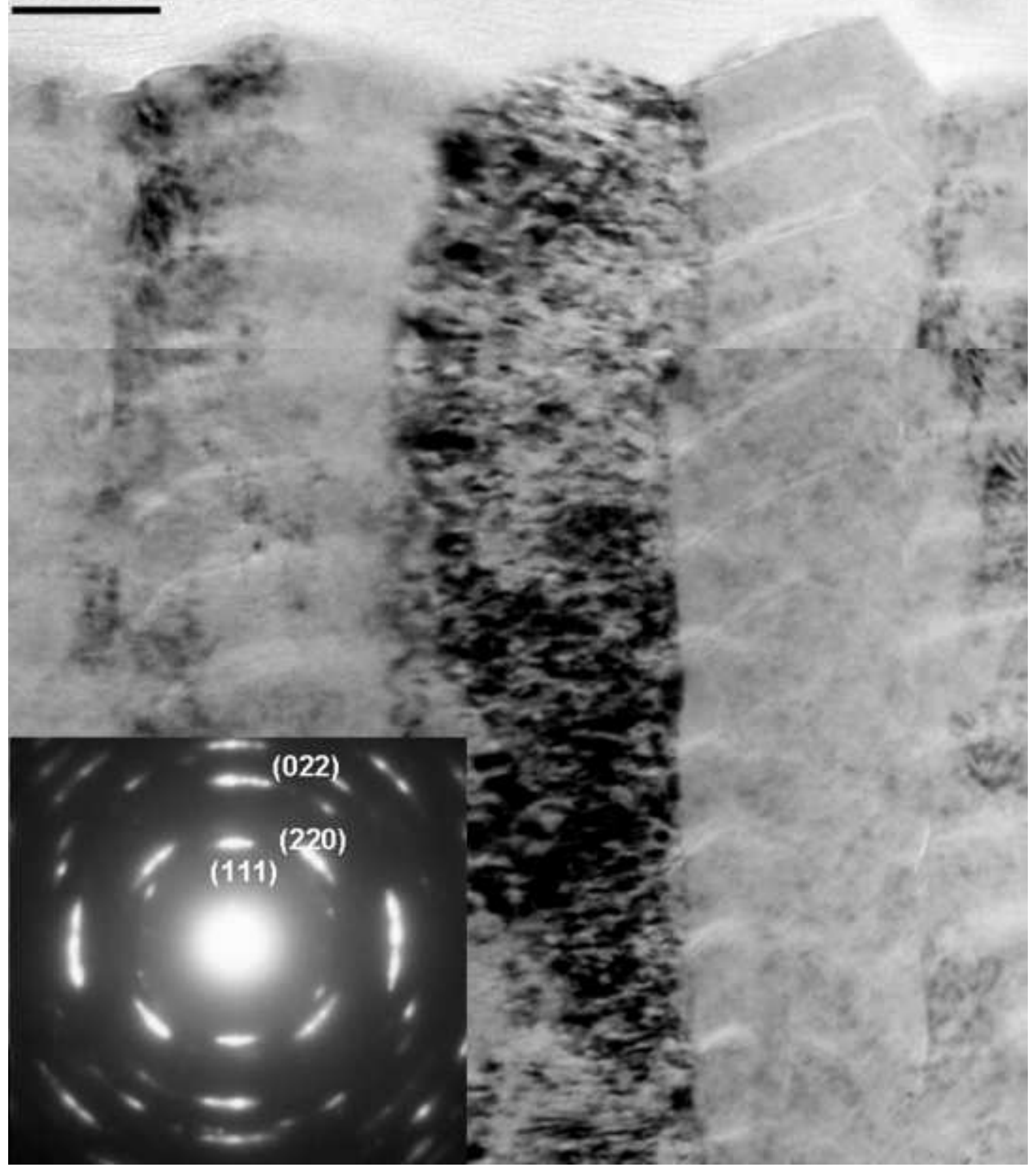


Figure(s)
Click here to download high resolution imag

Figure(s)
Click here to download high resolution image

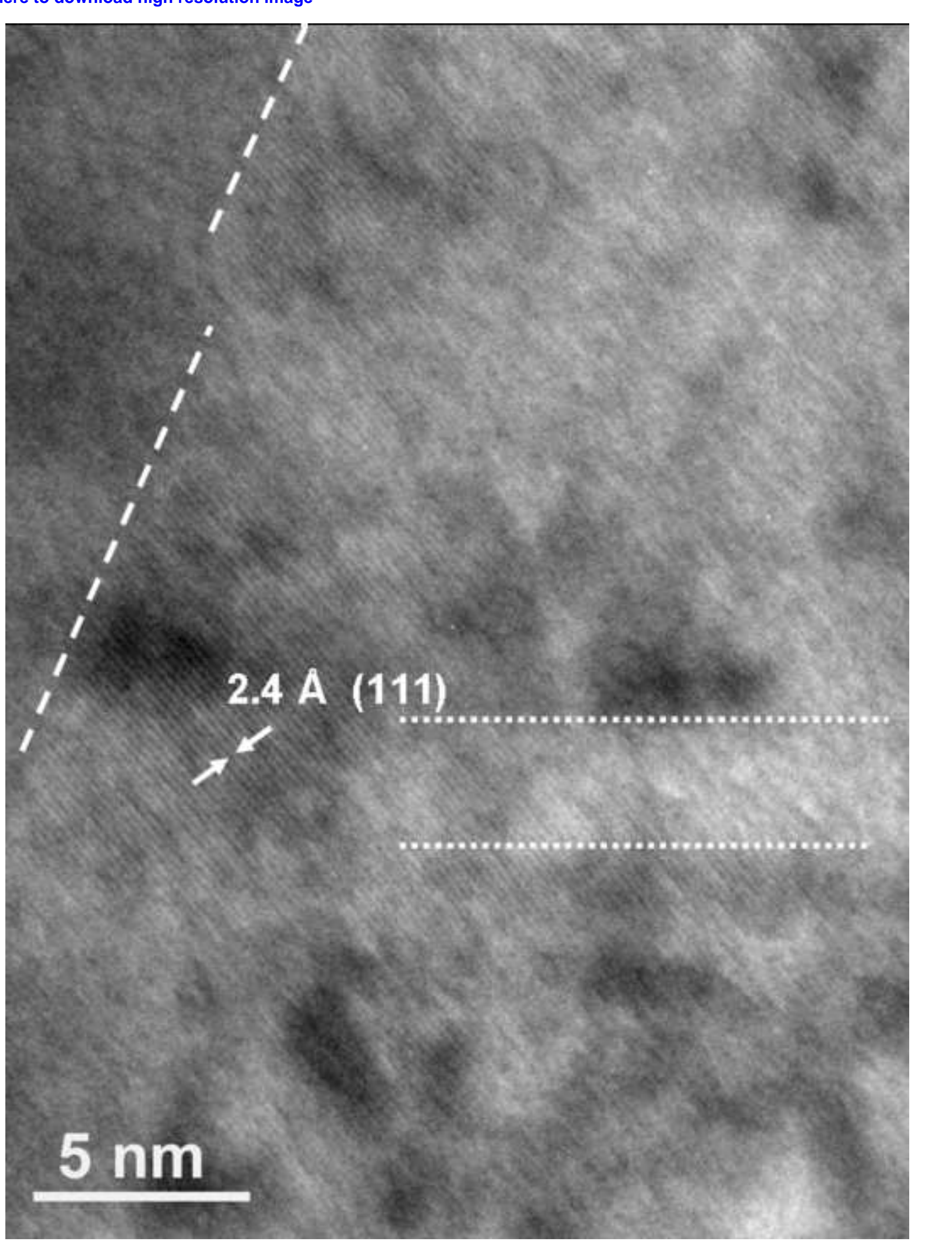

$5 \mathrm{~nm}$
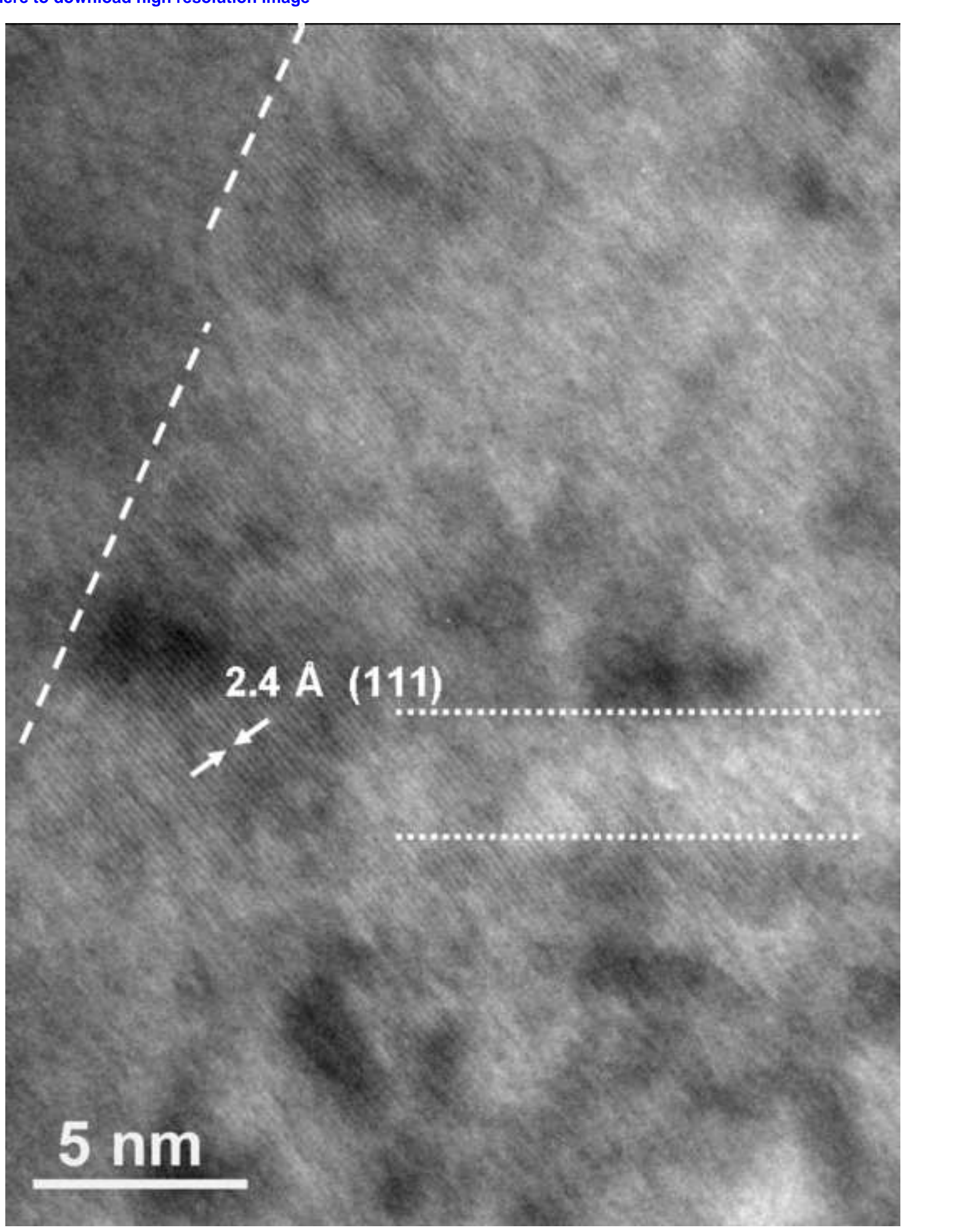


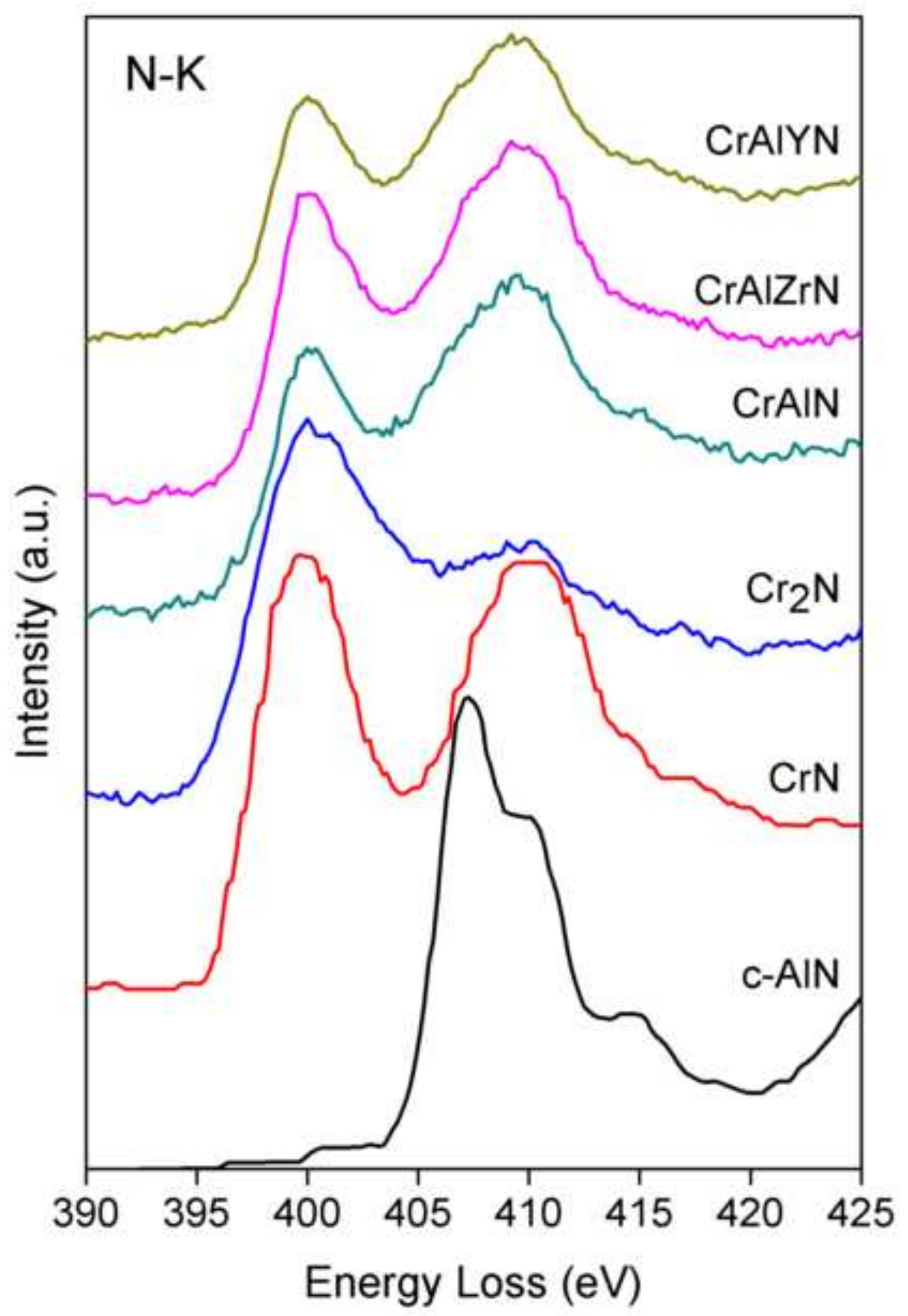




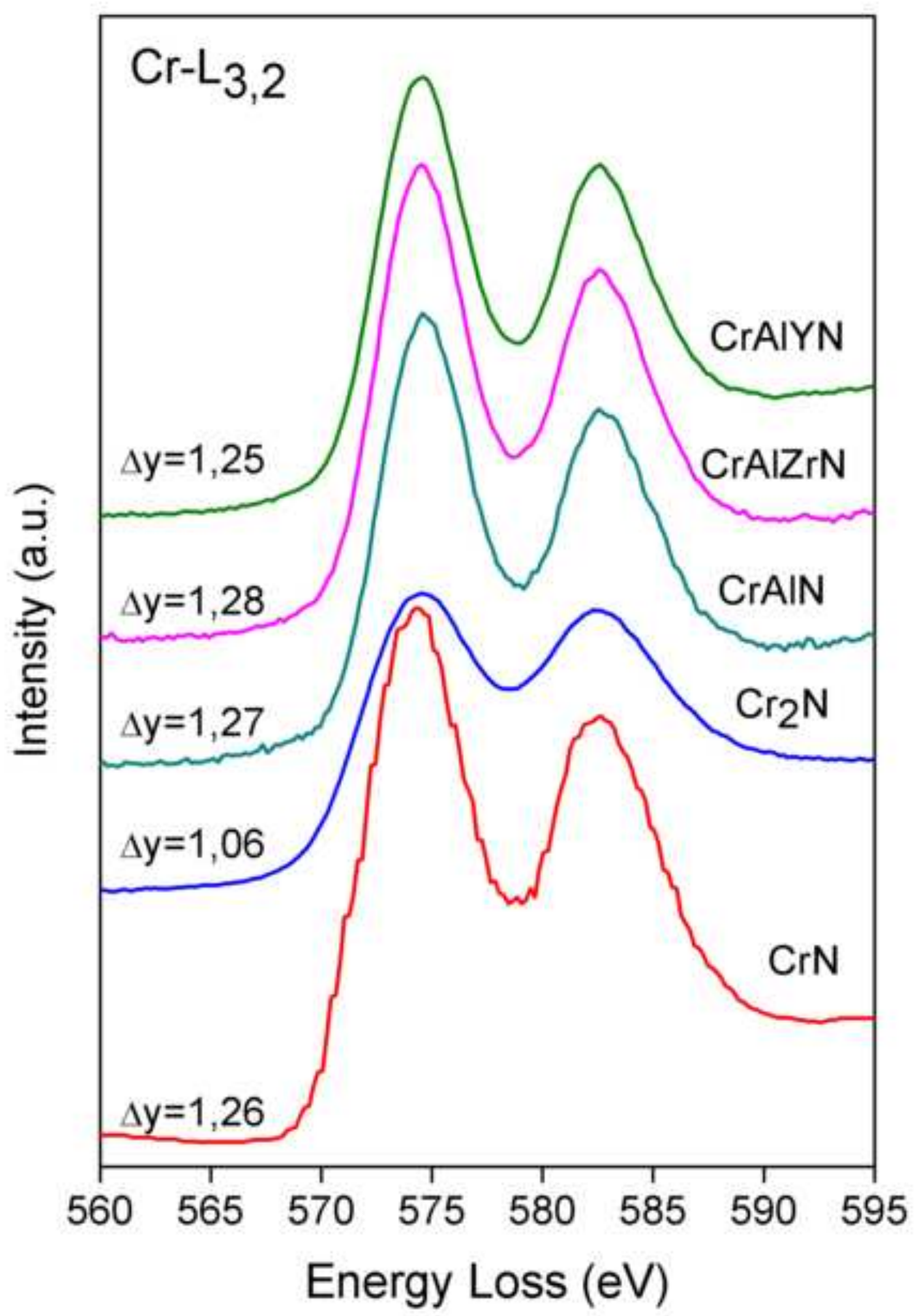




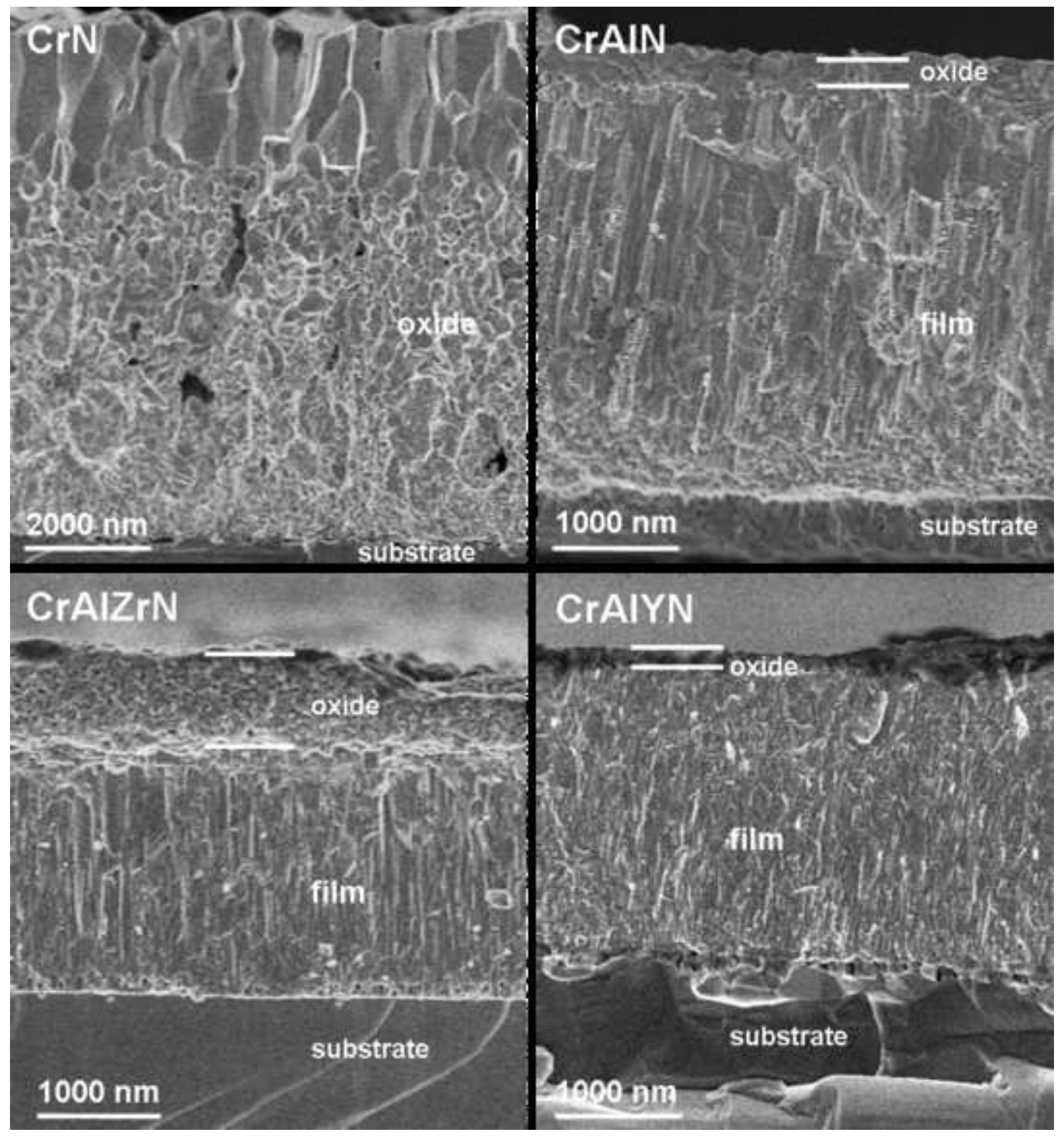




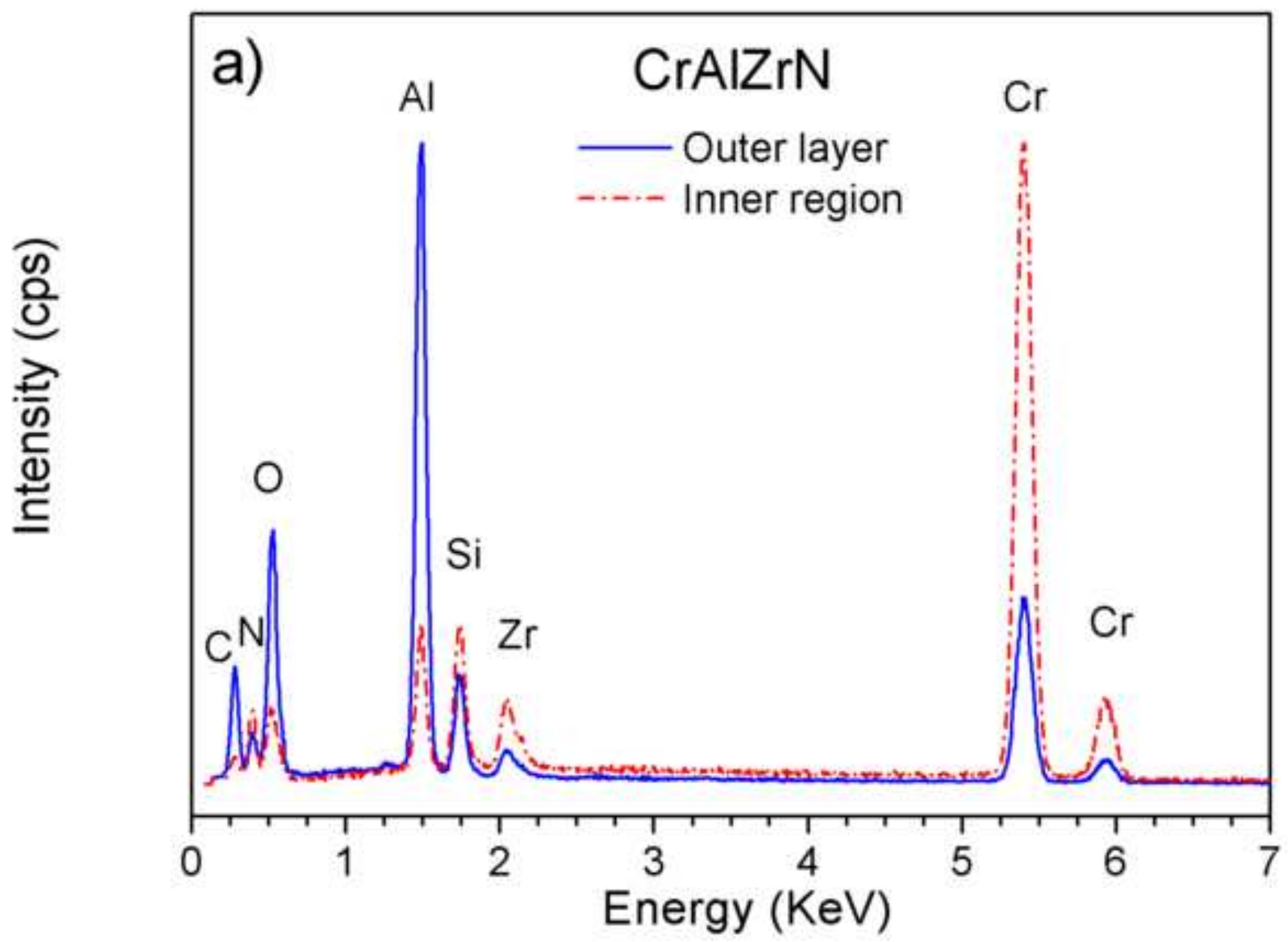




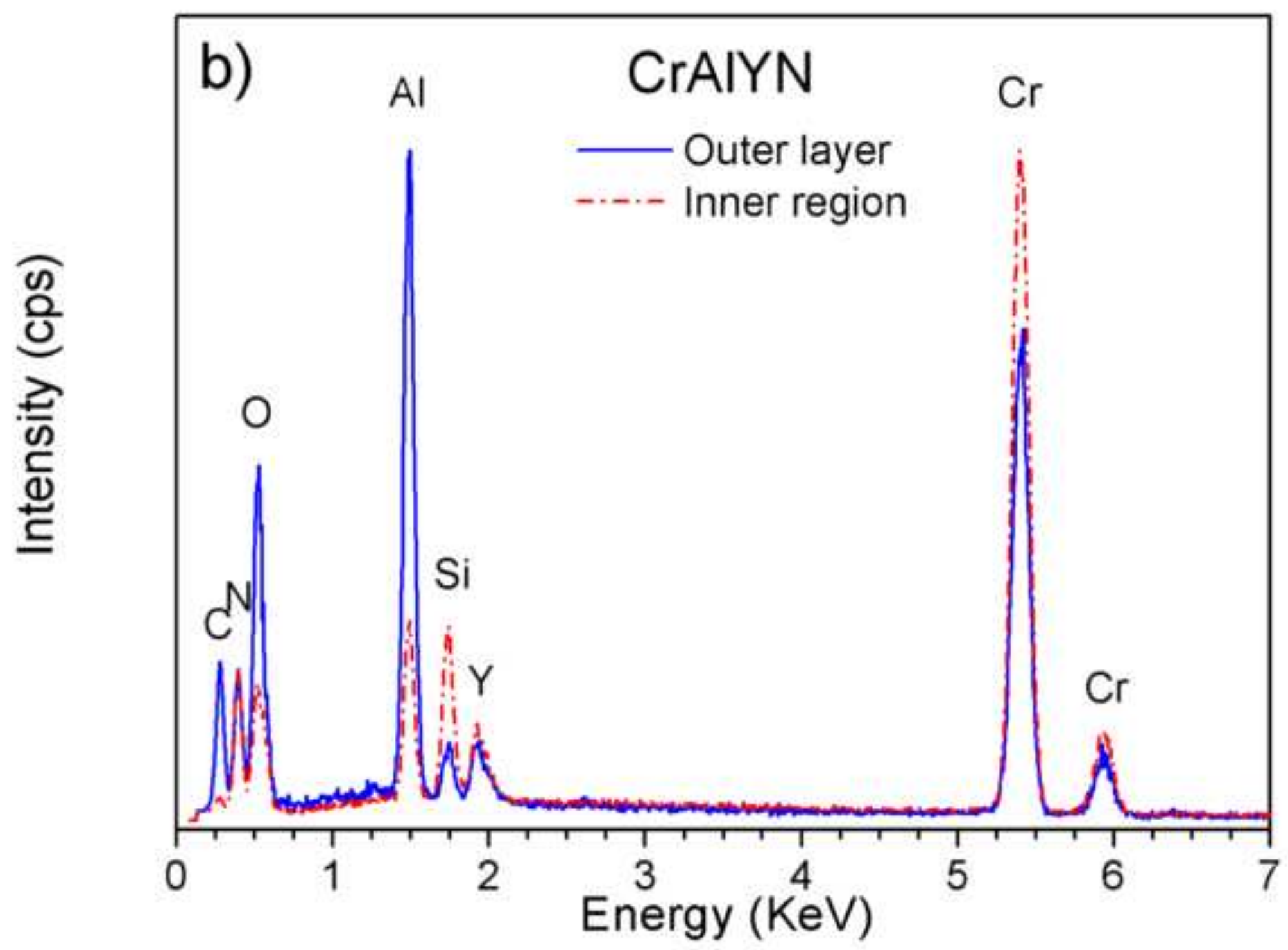




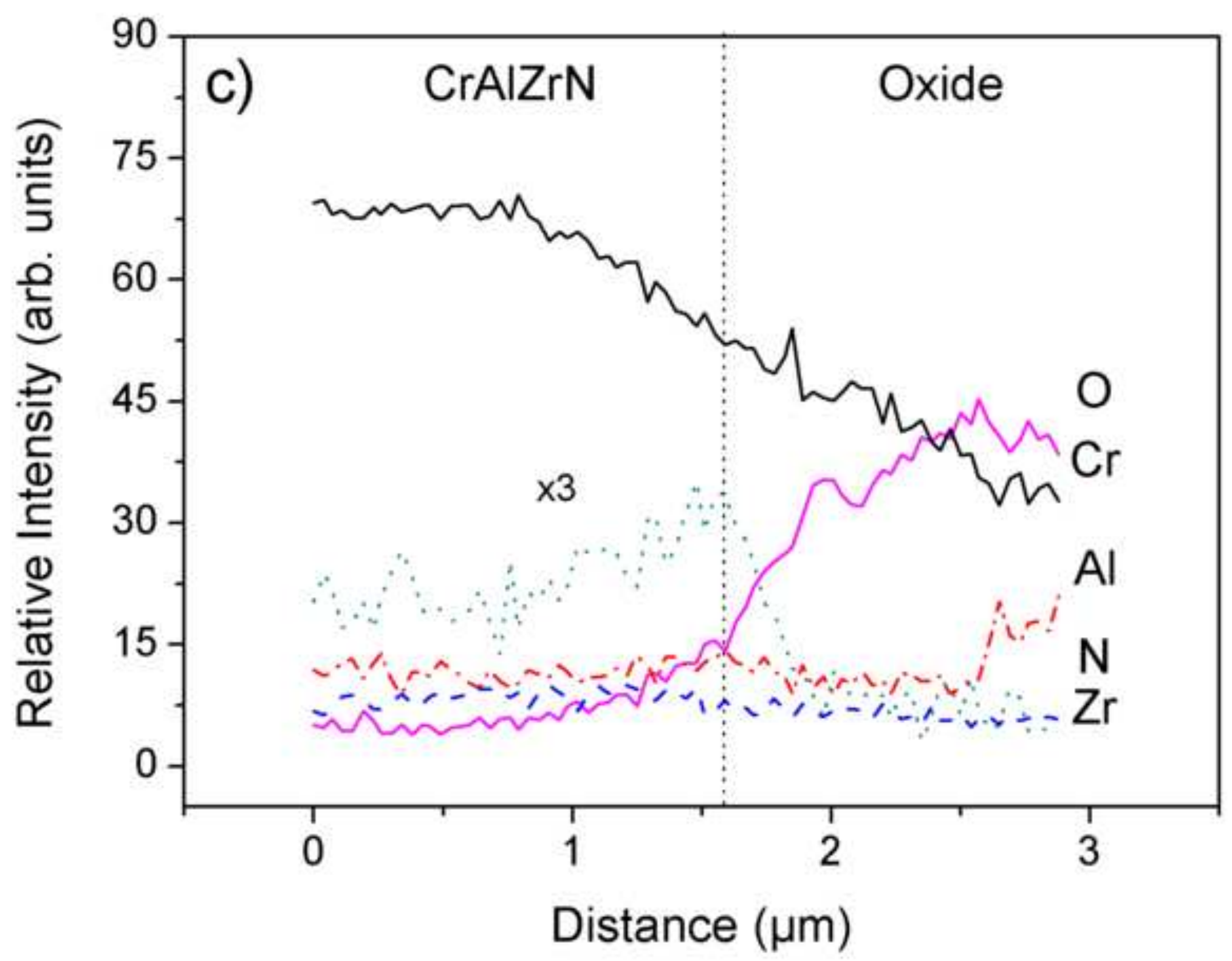




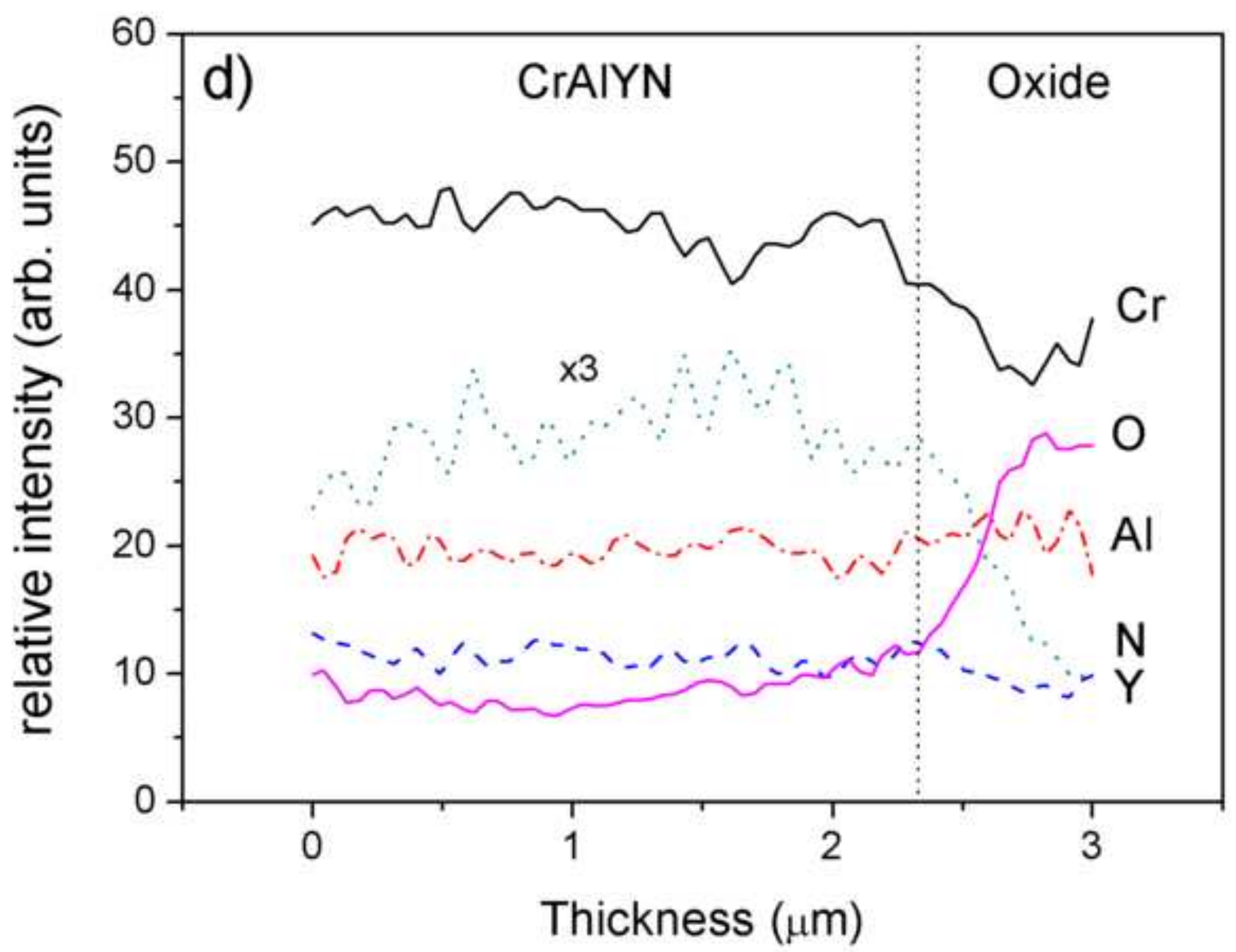




\section{Figure 8}

Click here to download high resolution image

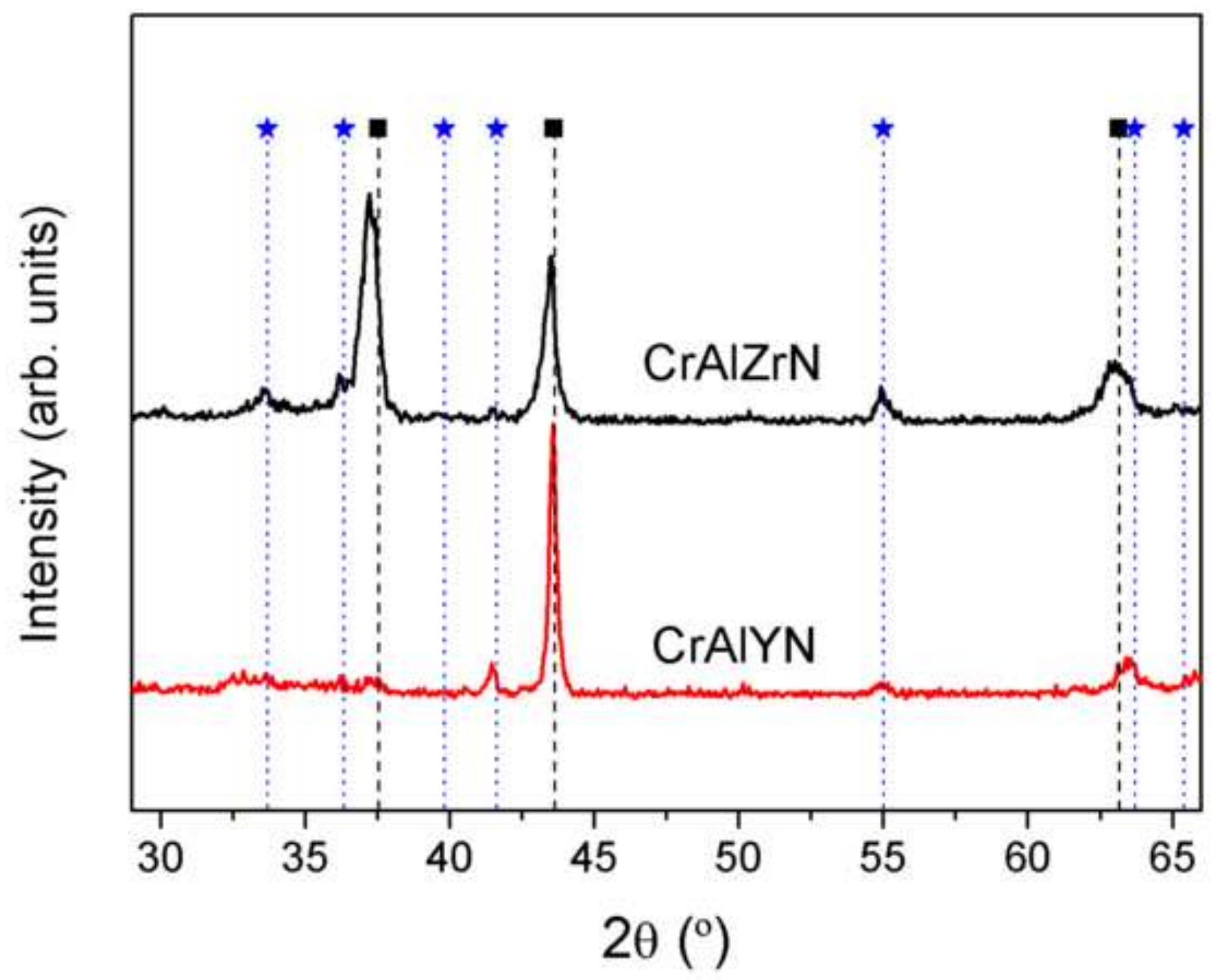




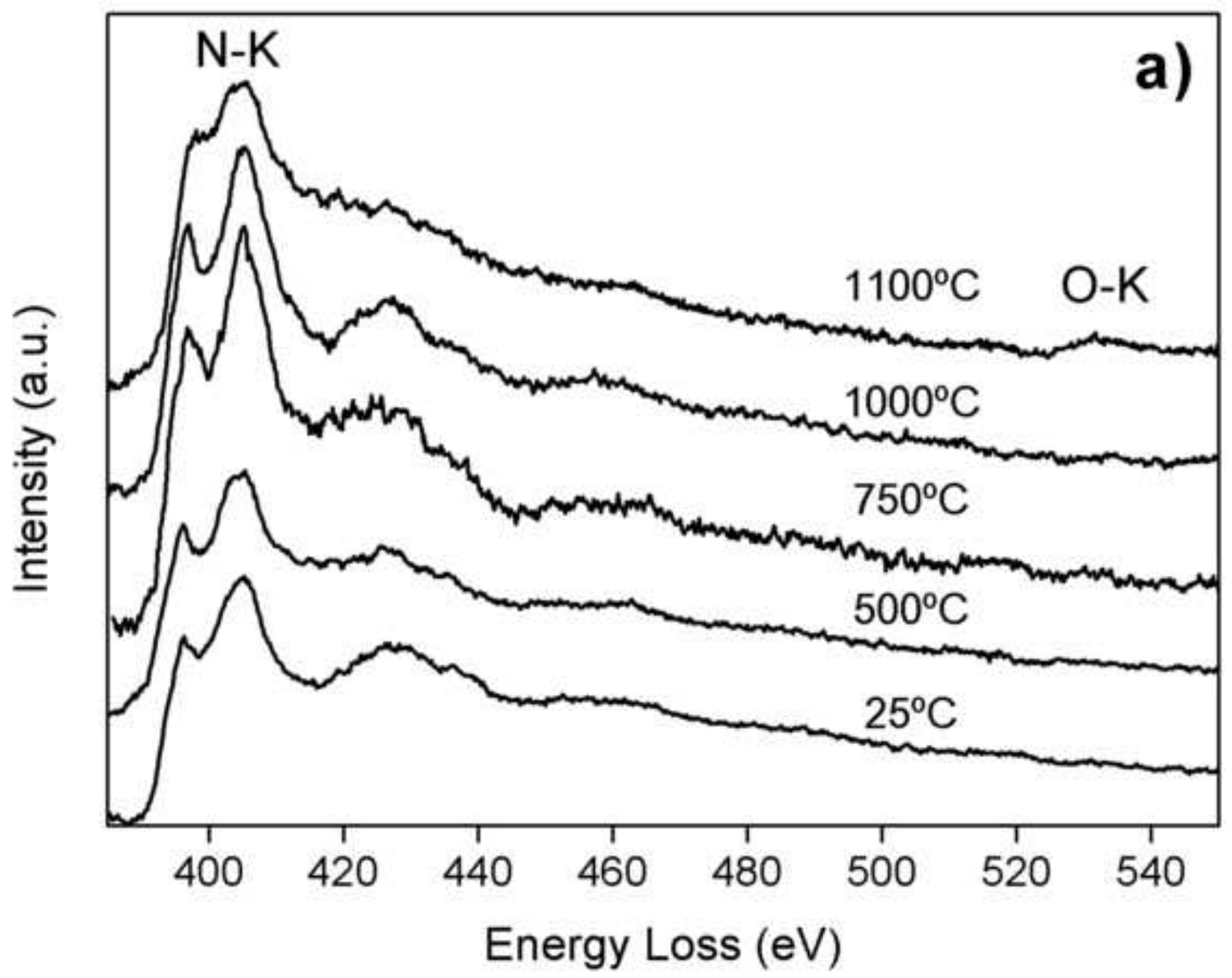


Figure 9b
Click here to download high resolution image

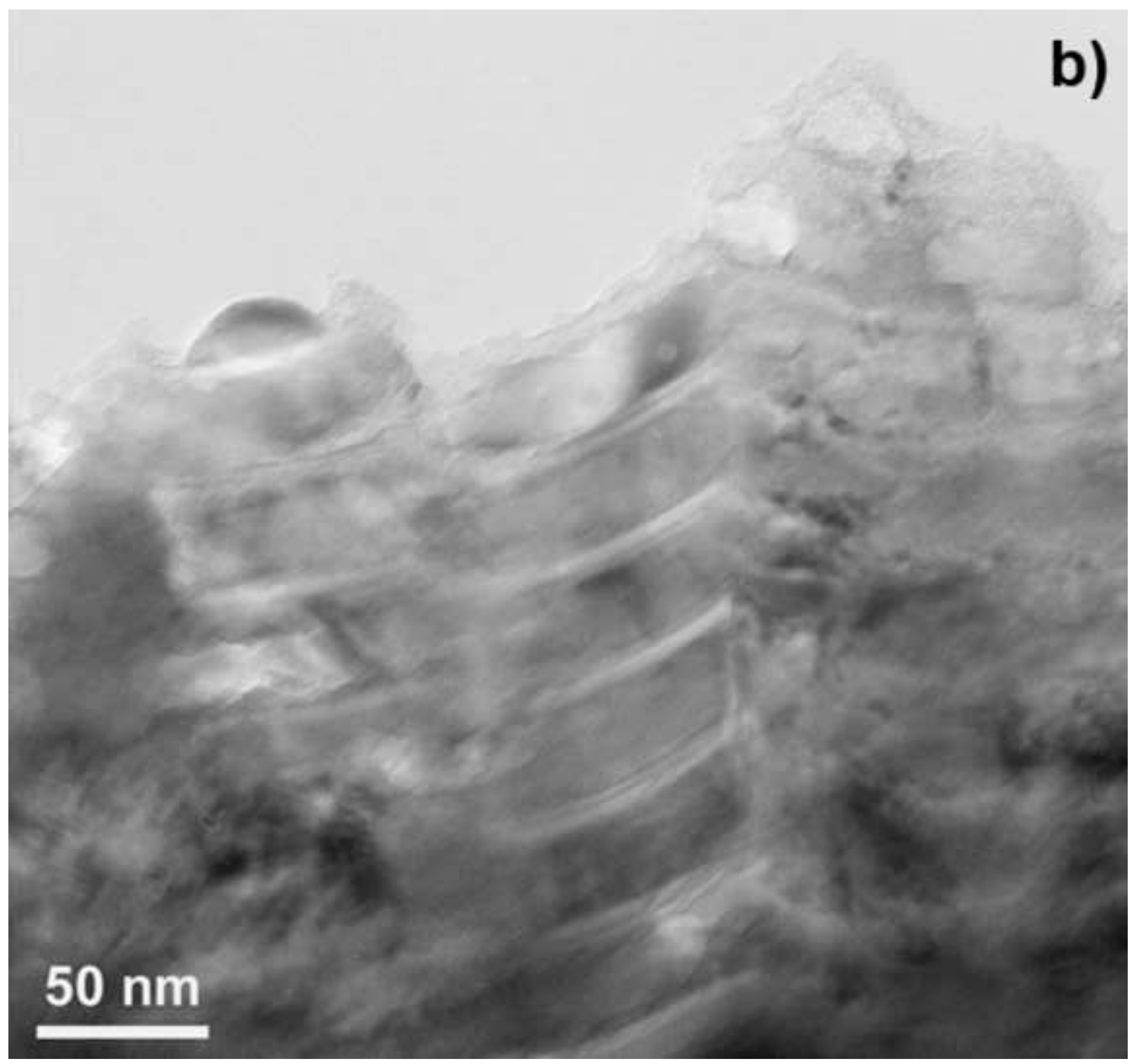

\section{$50 \mathrm{~nm}$

